\title{
Building and Occupant
}

Characteristics as Determinants

of Residential Energy

Consumption

L. A. Nieves

A. L. Nieves

October 1981

Prepared for the U.S. Department of Energy under Contract DE-AC06-76RLO 1830

Pacific Northwest Laboratory Operated for the U.S. Department of Energy by Battelle Memorial Institute 
NOTICE

This report was prepared as an account of work sponsored by the United States Government. Neither the United States nor the Department of Energy, nor any of their employees, nor any of their contractors, subcontractors, or their employees; makes any warranty, express or implied, or assumes any legal liability or responsibility for the accuracy. completeness or usefulness of any information, apparatus, product or process disclosed, or represents that its use would nor infringe privately owned rights.

The views, opinions and conclusions contained in this report are those of the contractor and do not necessarily represent those of the United Srates Government or the United States Department of Energy.

PACIFIC NORTHWEST LABORATORY

operated by

BATTELLE

for the

UNITED STATES DEPARTMENT OF ENERGY

Under Contract DE-ACO6-76RLO 1830

\author{
Printed in the United States of America \\ Available from \\ National Technical information Service \\ United States Department of Commerce \\ 5285 Pori Rayal Road \\ Springfield, Virginia 22151
}

Price: Printed Copys.

$\because$ Microfiche 33.00

NTIS

-Pages Selling Price

001-025 $\quad 3400$

$026-050 \quad \$ 150$

$051.075 \quad 55.25$

076. $100 \quad \$ 6.00$

$107-125 \quad \$ 6.50$

126-150 57.25

$151-175 \quad 58.00$

$776-200 \quad 59.00$

$201-225 \quad 59.25$

$226-250 \quad 59.50$

$251.275 \quad 510.75$

$276-300 \quad 511.00$ 
BUILDING AND OCCUPANT CHARACTERISTICS AS DETERMINANTS OF RESIDENTIAL ENERGY CONSUMPTION

L. A. Nieves

A. L. Nieves

October 1981

Prepared for the U.S. Department of Energy under Contract DE-AC06-76RLO 1830

Pacific Northwest Laboratory Richland, Washington 99352 


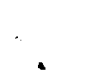

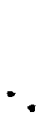




\section{ACKNOWLEDGEMENTS}

The authors wish to acknowledge the valuable assistance provided by Mary Ellen wand in handling the computer runs necessary for the statistical analysis. Thanks are also due to Richard Mazzucchi and Wally Hopp for their efforts in simulating energy consumption in the subdivisions as well as assisting in data collection arrangements. 


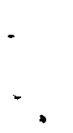
•


SUMMARY

This report describes the results of work undertaken for the U.S. Department of Energy, Office of Conservation and Renewable Resources. The DOE has had major responsibility for developing Building Energy Performance Standards (BEPS) to help reduce the energy consumption of newly constructed buildings. The study described in this report represents an exploratory, micro leve 1 investigation of energy consumption in single family residences and the implications for developing standards. Single family residences built in 1976-77 (old subdivision) are compared with similar residences completed by the same builder during 1979-80 (new subdivision). Building practices in both subdivisions were substantially the same except that the newer house incorporated several additional energy efficient features such as increased insulation. The relationship of building occupants' demographic characteristics, attitudes, and behavior to household energy consumption is also explored.

\section{RESEARCH GOALS}

This research was initially designed to achieve three major goals:

1. To gain insight into the probable effects of BEPS on energy consumption.

2. To obtain observations of actual residential energy consumption that could affirm or disaffirm consumption estimates of the DOE 2.0A simulation model.

3. To investigate home owner's conservation investments and home pur chase decisions.

\section{LIMITATIONS OF THE STUDY}

As an exploratory study this research provides insight into the problem area and may serve as a basis for later refinement at a relatively low cost. The nature of the research, however, generates some limitations. Among its limitations are: 
1. Small sample size which restricts the kinds of analysis possible. Parameter estimates and development of predictive models is limited.

2. Lack of data on residential fuel switching. Extensive use of wood in the old subdivision became apparent after preliminary analysis of the retrofit variables. Because only data on electricity consumption were collected, the study underestimates total (electricity and wood) Btu consumption.

3. Price. A lack of either substantial price variation or price uniformity (resulting from the subdivisions being served by two different utilities) clouds any conclusions concerning the impact of price on consumption.

\section{DATA COLLECTION}

The final sample consists of useable questionnaires with associated electricity and climate data for 35 households. Resulting data items fall within four categories: construction characteristics, electricity use, climatological data and occupant characteristics.

Construction characteristics included such variables as housing type, R-value of insulation and floor area. Climate data used in this study are rimited to heating-degree days which serve as a proxy for other climatic conditions. Electricity-use variables of concern were the average price per kilowatt hour and the quantity consumed. The consumption variable was standardized as Btu per heating-degree day per square foot (Btu/HDD/Ft ${ }^{2}$ ). Occupant characteristics incorporated demographic, attitudinal and behavioral measures.

\section{DATA PRESENTATION AND ANALYSIS}

This section begins with a presentation of descriptive statistics for the sample as a whole. It proceeds to a comparison of the old and new subdivision and concludes with a discussion of the relationship between independent and dependent variables and among key independent variables. 
The median house size for the total sample was $1264 \mathrm{ft}^{2}$. Only four houses contained more than $1400 \mathrm{ft}^{2}$. The range of energy consumption, however, was quite large with the highest consumption of Btu per heating degree day approximately four times the lowest. The houses were generally occupied by from two to four people $(R=2.97)$. The adults had some college education and annual family incomes fell in the $\$ 30,000$ to 40,000 range.

In comparing subdivisions (using the $t$ test for difference between means) only two demographic variables emerged as significantly different. They are the number of adults occupying a residence (higher in the old) and annual family income reported (higher in the new). Comparison of behavioral differences across subdivisions revealed a significant difference only for the winter night thermostat setting. Although nonsignificant, the winter day temperature difference is in same direction and is the next most significant behavioral variable.

Examination of retrofit behavior showed that fifty percent of the old subdivision residents had installed woodstoves. A comparison was then made of households with and without woodstoves. Significant differences were discovered in a number of variables, the most important of which was electricity consumption (significant at the .01 level).

Bivariate relationships were explored using the Pearson correlation coefficient, $r$. Examination of the zero order correlations between the independent variables and Btu/HDD/Ft ${ }^{2}$ consumed for the sample as a whole revealed few significant relationships. Only total occupants $(r=.38, p=.02)$ and winter day temperature $(r=.26, p=.07)$ were significant. When examining each subdivision separately, however, a number of other relationships were apparent. For the old subdivision, total occupants was significant but thermostat setting was not. The retrofit variables introduced several significant assocations, with the most important being the installation of a woodstove.

For the new subdivision total occupants was again significant while winter day temperature increased in significance over the value for the total sample. The number of appliances appears significant for this subdivision, as does one attitudinal item. 
SIMLATION VS. ACTUAL ELECTRICITY CONSUMPTION

The simulation of energy requirements indicated lower requirements for the newer homes of a 11 model types. In contrast, actual measurement indicated higher consumption in the new subdivision except in the two story homes. Since heating with wood could displace upwards of 50 percent of the heating load, it is probably the single most important reason for discrepancies between simulated and actual consumption. Other possible reasons include: differences in internal load resulting from number of occupants and appliances, lighting use patterns, modeling assumptions and thermostat settings.

\section{INVESTMENT AND PURCHASING DECISIONS}

To investigate the questions, (1) whether and (2) to what degree market incentives are resulting in energy conservation, households were surveyed regarding their decisions to purchase housing and to make energy conserving investments. Respondents generally indicated a concern with energy conserving features and a willingness to make energy conservation investments. The most important factor in motivating investment seemed to be information as to the likely energy and cost savings of particular features.

ORGANIZATION OF THE REPORT

The first chapter following the introduction deals with the determinants of household energy consumption, beginning with the underlying economic theory and implications and proceeding to discussion of data collection, variable formulation, data analys is and findings. The second chapter addresses the assumptions and limitations of the energy use projections of the DOE 2.0A simulation model and compares actual and predicted consumption. The third chapter explores energy conserving investments and acceptance of various conservation features. The final chapter presents conclusions and recommendations with an emphasis on policy implications of the study. 


\section{CONTENTS}

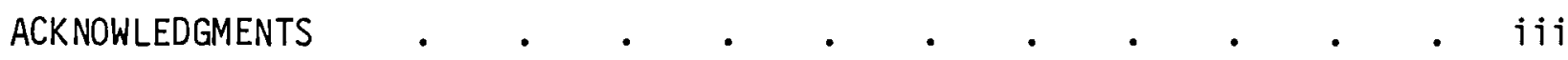

SUMMARY

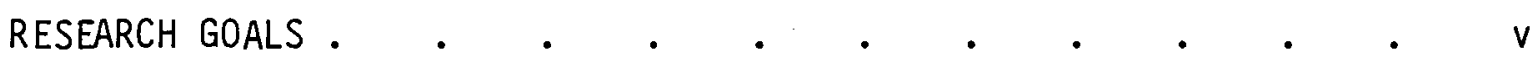

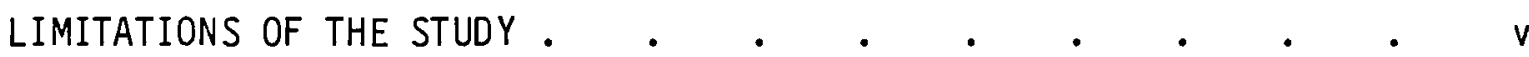

DATA COLLECTION

DATA PRESENTATION AND ANALYSIS $\quad$. . . . . . . . . . . vi vi

SIMULATION VS. ACTUAL ELECTRICITY CONSUMPTION $\quad \cdot \quad \cdot \quad \cdot \quad$ • viii

INVESTMENT AND PURCHASING DECISIONS $\quad \cdot \quad \cdot \quad \cdot \quad \cdot \quad \cdot \quad \cdot \quad \cdot \quad$ e viii

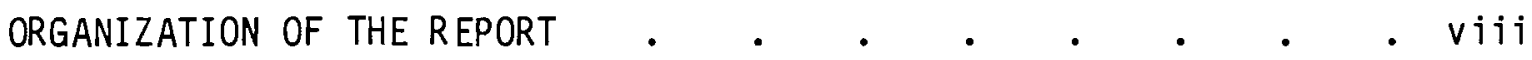

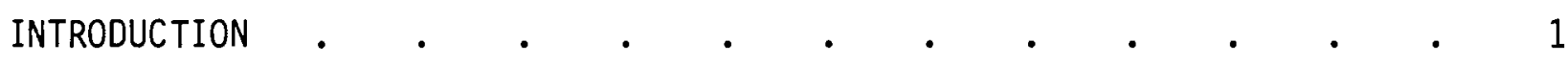

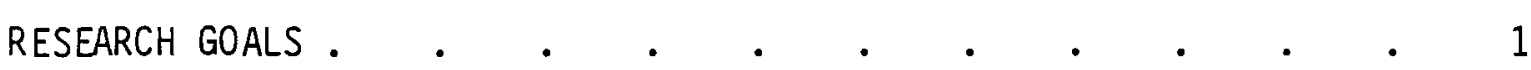

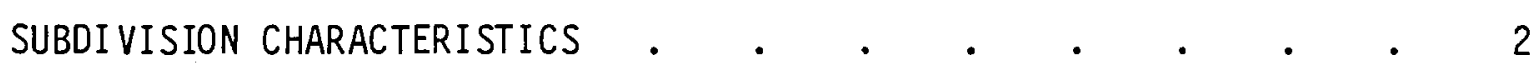

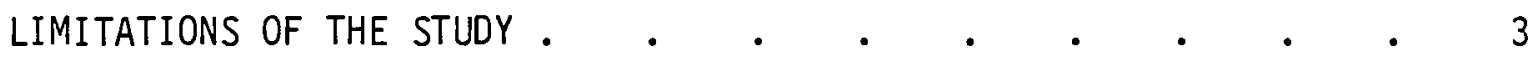

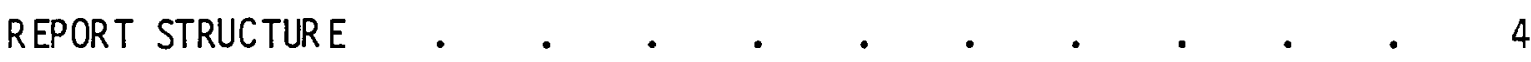

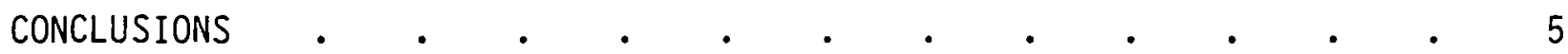

DETERMINANTS OF ENERGY CONSUMPTION

THEORY

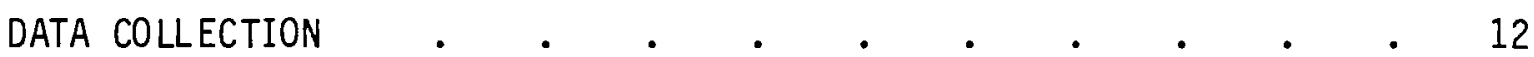

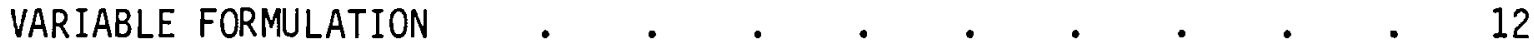

Construction Characteristics . $\quad . \quad$. $\quad . \quad$. $\quad . \quad$. 14

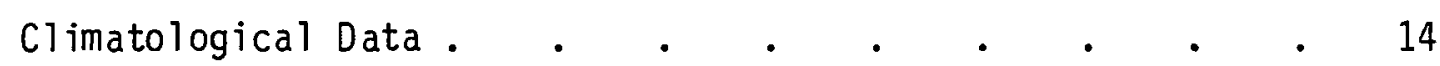

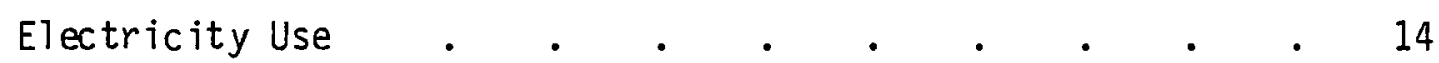

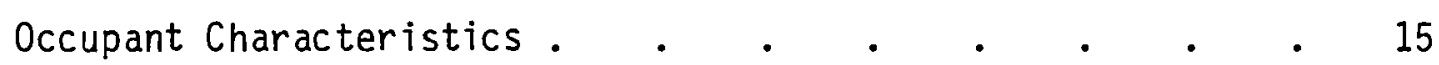

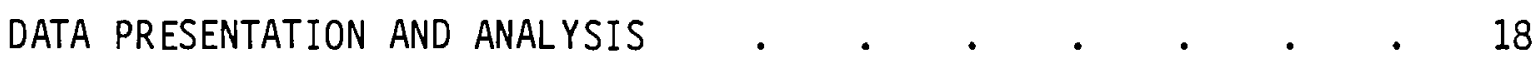




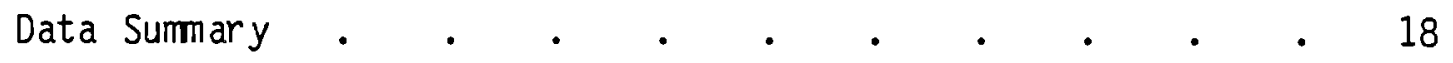

Group Comparisons . . . . . . . . . . 20

Variable Relationships . . . . . . . . . 26

SIMULATED AND ACTUAL ENERGY CONSUMPTION . • • • • • • • • 35

SIMULATION OF ENERGY CONSUMPTION

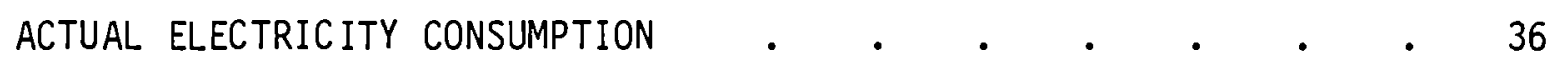

COMPARISON OF RESULTS

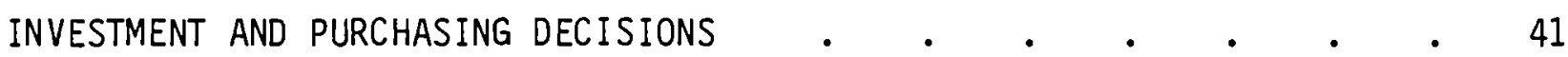

FACTORS IN DECISION MAKING

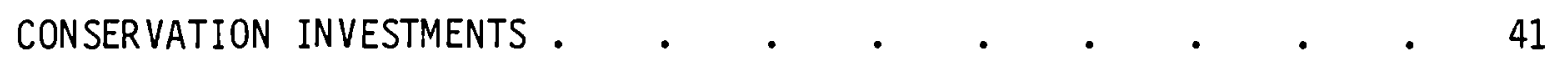

SUMMARY • • . . . . . . . . . . . . . . 43

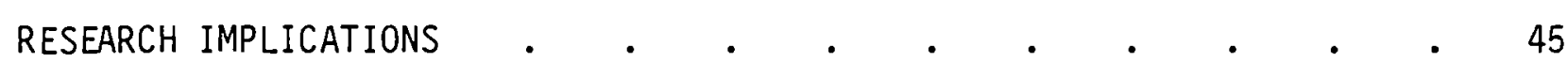

POLICY IMPLICATIONS • • • • • • • • • • • • 45

METHODOLOGICAL IMPLICATIONS •

APPENDIX A - HOMEOWNER'S QUESTIONNAIRE • • • • • • • • • A.I

APPENDIX B - HOMEBUYER'S QUESTIONNAIRE . . . . • . . • . B B.1 


\section{FIGURES}

1. The Marginal Product of Energy Given 01d and New Space Conditioning Technologies

2. Space Conditioning Choices under Two Relative Energy Prices . . 9

3. Response of Building Owners to Increased Real Energy Costs . . 11 


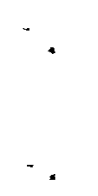




\section{TABLES}

1. Sources and Types of Energy Consumption Related Data . $\quad$ - 13

2. Description Statistics for the Total Sample $\quad$. $\quad . \quad$. $\quad$. $\quad 19$

3. Comparison of Demographic Characteristics Across Subdivisions - 21

4. Comparison of Behavioral Characteristics Across Subdivisions $\quad 23$

5. Percentage of 01d Subdivision Houses With Various

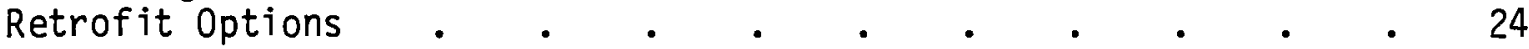

6. Comparison of Temperature Settings Within the 01d Subdivision $\quad 25$

7. Comparison of Electricity Consumption for Heating Across Subdivisions . $\quad$ • . . . . . . . .

8. Zero Order Correlations $(r)$ of Btu/HDD/Ft2 with Selected Independent Variables . . . . . . . . 28

9. Zero Order Correlations of Btu/HDD/Ft2 in the 01d Subdivisions with Selected Independent Variables . . . . . 29

10. Zero Order Correlation of Btu/HDD/Ft2 in the New Subdivisions with Selected Independent Variables . . . . . 31

11. Zero Order Correlations Between Attitudinal Variables and Selected Other Independent Variables $\quad$. $\quad . \quad$. $\quad . \quad$ e 33

12. DOE 2.0A Simulations for the Subdivisions . . . . . . . 37

13. Actual Electricity Use During the Heating Season . . • • 38

14. Comparison of Mean Temperature Settings and

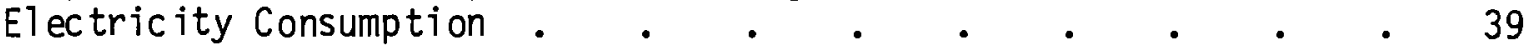

15. Comparison of Simulated and Actual Electricity Use

16. Factors Reported to Affect House Purchase DecisionsListed in Order of Importance . . . . . . .

17. Factors Influencing Respondents' Energy Conservation Investment Decisions $\quad . \quad . \quad . \quad . \quad . \quad . \quad$.

18. Respondent Willingness to Pay an Additional $\$ 600$ for a Home to Save $\$ 100$ in Energy Costs Annually . . . . . . . 43

19. Acceptability of Energy Related Features to Homeowners . . 44 


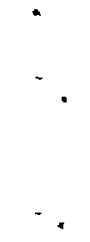




\section{INTRODUCTION}

The U.S. Department of Energy has had major responsibility for developing Building Energy Performance Standards (BEPS) to help reduce the energy consumption of newly constructed buildings. Both the potential effectiveness and possible impacts of the proposed BEPS have been the subject of considerable research and controversy. This study provides an exploratory micro level investigation of the energy savings in residential buildings likely to result from implementation of BEPS and the relationship of building occupants' demographic characteristics, attitudes and behavior to household energy consumption.

\section{RESEARCH GOALS}

This study was designed to address three major goals related to development of BEPS. One of these goals was to gain insight into the probable effects on energy consumption of instituting BEPS. For this purpose, actual observations on energy consumption in houses built to BEPS standards were desired for comparison with observations for houses built to meet minimum building code requirements. At the time of this study's inception, proposed energy budget levels for BEPS were undergoing revision. Because the final BEPS budget levels were uncertain, the first goal of this research could not be fully realized since the new houses analyzed were not "BEPS" houses. They incorporate relatively energy efficient, but not necessarily minimum life-cycle-cost, construction techniques. This research provides a comparison of energy consumption in these relatively energy efficient homes with consumption in conventional homes facing the same general climatic conditions. To permit a meaningful comparison of energy consumption in the two groups of homes, information was gathered about house and occupant characteristics. The resulting data allowed some analys is of relationships of structural characteristics of the houses and demographic, attitudinal and behavioral characteristics of the occupants to energy consumption. 
A second goal of the study was to obtain observations of actual residential energy consumption that would corroborate energy consumption estimates of the DOE 2.0 simulation model. To this end energy consumption of the various home models included in the subdivisions was modeled using DOE 2.0 Energy consumption estimates were produced for the relevant levels of insulation, window glazing and the space conditioning systems installed. These estimates were compared with utility data for the occupied homes.

The third goal of this exploratory study was to investigate home owners ' conservation investments and home purchase decisions. Some indication of the relative importance of energy costs and possible energy savings to homeowners may be gained from the survey information gathered.

\section{SUBDIVISION CHARACTERISTICS}

This study of energy consumption patterns took advantage of a relatively unique opportunity for quasi-experimental research. In 1979 a construction firm agreed to work with PNL in evaluating and applying energy conserving building design. The firm had constructed one residential subdivision 3 years previously and was planning another subdivision in the same town using several of the same house designs. The builder agreed to provide cost and design information for both the old and new subdivisions and to obtain energy use related information from the residents. The builder's willingness to incorporate energy conserving options in the new subdivision and the existence of an older, conventional subdivision which would serve as a benchmark, provided a good opportunity to explore potential impacts of energy efficient construction practices in detail.

The subdivisions involved in this research were built by the contractor during 1976-77 and 1979-80. House designs are similar in the subdivisions and building practices did not differ substantially. All of the residences are conventional, low to mid-priced, slab-on-grade houses with electric heating and central air conditioning. In appearance and general construction techniques, the houses are comparable to other houses in their price range and were built to sell competitively on the speculative market. 
Throughout this report, the subdivision built in 1976-77 is referred to as the "old" subdivision. It is located in Hermiston, Oregon which is about 45 miles from the Pacific Northwest Laboratory. Houses in the old subdivision were built with R-11 wall and R-22 ceiling insulation and double-glazed windows and many of the homes had attached unheated garages. Electricity for the eighteen homes included in the sample is provided by a private utility.

When this research effort was designed, a large new subdivision was planned in Hermiston within a mile or so of the old subdivision. The housing slump of 1980, however, resulted in fewer than 10 new houses being completed by 1981. To increase the number of observations $(N=17)$, new houses of similar design, constructed by the same builder at about the same time and located in a similar subdivision in Kennewick, Washington, were included. Kennewick is located approximately 30 miles north of Hermiston and has similar climatic characteristics. Because of their similarity, the Kennewick and Hermiston subdivisions are treated as one and are referred to as the "new" subdivision. Both are served by public utilities and face virtually the same electricity price. The price is and has been approximately half that charged by the private utility serving the old subdivision. In the new subdivision, walls and ceilings were insulated to R-19 and R-38 although Oregon and Washington building codes required only $R-11$ and $R-30$, respectively. Some of the new homes have triple glazing and all have perimeter insulation around the foundations although these features are not required by code. Additionally, all of the new houses have wood stoves or heatilator fireplaces.

\section{LIMITATIONS OF THE STUDY}

Exploratory research such as this is useful in providing insight into energy consumption decisions and can be used as the basis for designing a more definitive analysis of household patterns of energy consumption. Due to the small sample size it is not as useful for parameter estimation or development of a predictive model of energy consumption as it might otherwise be. In addition, there are problems of missing informaton that make it impossible to test some important hypotheses with the present data. For instance, it became apparent in the course of the data analys is that some of the households in the old subdivision probably use wood as their primary heating fuel. Since no 
information was collected on wood consumption, the data understates total (i.e. electric plus wood) energy consumption in these homes. Since the houses were not physically monitored, indoor temperature information is also unavailable. As a result, quantities of energy provided by burning wood cannot be inferred from the data.

Additionally, use of the data is limited by the lack of either substantial electricity price variation or constant price across subdivisions. In designing the research the possibility that a town with a population of 5,000 could be served by two different utilities was overlooked. The public utilities serving the new subdivision charge one half the rate of the private utility serving the old. Given the lower price of electricity in the new subdivision one would expect electricity consumption to be greater there than in the old even if the buildings were identical. Adding the effect of lower price to greater energy efficiency in the form of a lower marginal cost of space conditioning intensifies the incentives for higher levels of electricity consumption .

\section{REPORT STRUCTURE}

Chapters of this report correspond to the major goals of the research effort. The first chapter covers the investigation of determinants of household energy consumption. The presentation begins with the underlyng economic theory and its implications, and continues with a description of the data collection procedures, the formulation of variables and then of data analys is and findings. In the second chapter the assumptions and limitations of the energy use projections generated by the DOE 2.0A model are discussed. Actual electricity data for the houses are then compared with results of the simulation. The third chapter contains information regarding households' willingness to make energy conserving investments and their ranking of various conservation features. In the final chapter conclusions and recommendations are presented with an emphasis on the policy implications of this study. 


\section{CONCLUSIONS}

The results of this study indicate that a clear point of reference is needed from which to measure energy conservation. An energy efficient house will require less energy for space conditioning to a given comfort level than an otherwise identical house with an identical pattern of occupant use. Thus, installation of efficient technology does result in energy conservation. However, an energy efficient house will not necessarily use less energy than an inefficient one in which lower comfort levels are maintained or in which the pattern of use is less energy intensive. As a result, care is required to avoid confusion of the effects of technology on energy use with the effects of behavior.

In addition to difficulties in measuring conservation, there are problems in accounting for conservation. Much of the reduction in electricity usage in the old subdivision houses with woodstoves does not represent energy conservation per se, but is actually due to substitution of wood combustion for electricity in space heating. Capital investment which permits fuel substitution in buildings, unlike capital investment in insulation, results in electricity demand reduction that is totally dependent on occupant behavior rather than being total energy demand reduction. Should any wood supply or demand change result in higher wood prices relative to electricity, house occupants may adapt to the change by switching back to electricity. 



\section{DETERMINANTS OF ENERGY CONSUMPTION}

This analys is is largely exploratory in nature in that it attempts to identify the variables and interrelationships which appear to most critically influence energy consumption. Once the interrelationships between variables are established, further research may then focus on developing predictive models utilizing regression analys is or other appropriate multivariate techniques, provided a sample of adequate size is available. Indeed, the goal of a largely exploratory study such as this is to raise questions and guide future research. The discussion which follows presents the theoretical framework of the analysis, the rationale for the variable formulation, the procedures and findings of the statistical analysis, and some thoughts on the implications for future research and policy formulation.

\section{THEORY}

The rationale for implementation of Building Energy Performance Standards stems from the reasonable assumption that energy can be saved (and oil imports reduced) by designing buildings to use energy for space conditioning more efficiently. The difference in the marginal product of new, energy efficient and older inefficient technologies is shown in Figure 1 . For both the old and the new homes, the energy required to maintain a given indoor temperature will vary with the difference between the indoor and outdoor temperatures, among other factors. However, the space conditioning system in the new houses is designed so that the marginal product of energy is greater at all indoor temperature levels (where the marginal product is defined as the temperature change per Btu input). The imposition of building standards focuses on the technology used in the space conditioning of buildings, rather than on the behavior of building occupants. Maintaining comfortable temperatures in buildings actually depends on the interaction of the building structure and equipment with the exterior temperature, solar radiation, interior humidity, velocity of air movement, appliances and a broad range of occupant behaviors. 


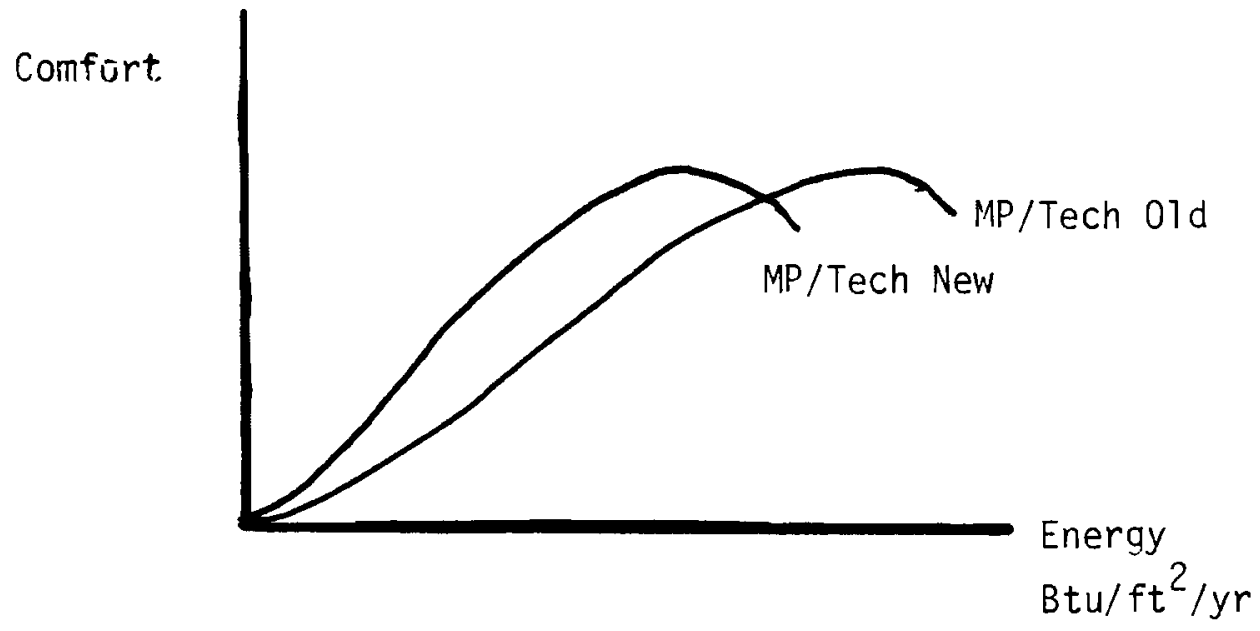

FIGURE 1. The Marginal Product of Energy Given 01d and New Space Conditioning Technologies

The effects of exterior temperature and building shell interactions on space conditioning have received much more attention than the other factors in these complex systems. Occupant behaviors and the forces underlying them merit investigation, since actions such as leaving doors open, or changing the thermostat setting can offset energy savings gained from increased insulation. Implementation of efficiency standards may not result in the desired energy savings if the incentives confronting building occupants do not encourage energy conserving behaviors.

The technology embodied in a house creates economic constraints and incentives for the occupants and affects their investment and consumption decisions. older space conditioning technology formerly represented the life-cycle-cost minimizing point prior to the structural change in energy prices that occurred during the early seventies but no longer does. With present energy prices the life-cycle-cost of space conditioning is lower with the new, more energy efficient technology than with the old. As a result, occupants of energy efficient buildings may, other things being equal, have a higher disposable income level, after total space conditioning expenditures, than occupants of equivalent 
buildings with relatively inefficient space conditioning systems. A higher disposable income allows occupants to purchase more energy as well as other goods.

Figure 2 uses a comparative statics framework to illustrate the choice of space conditioning technology under two relative energy prices. Insulation levels are used to represent the differences in space conditioning technology while house structure and income are assumed to be constant. An increase in energy costs relative to insulation costs results in movement from the formerly optimal technology (Point 0 ) to a new cost minimizing point (Point $N$ ) that is more capital intensive. Note that the isocost lines in this figure are not fixed budgetary limits since the space heating budget is a variable portion of the household's total income. Relative building insulation and

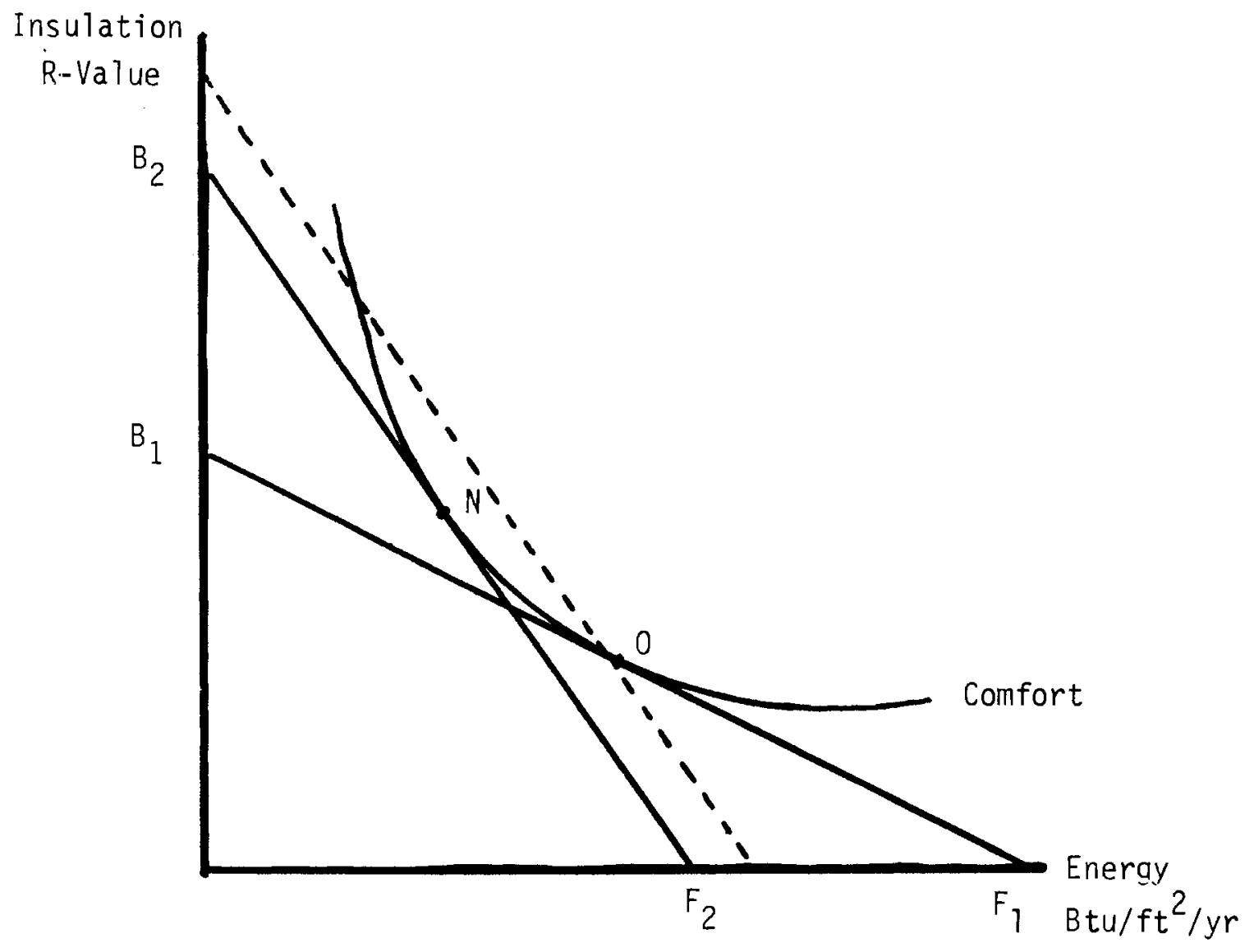

FIGURE 2. Space Conditioning Choices under two Relative Energy Prices 
energy quantities under which the old subdivision technology was least cost are shown by line $B_{1} F_{1}$. The least cost combination of energy and insulation under higher, relative energy prices is shown by line $\mathrm{B}_{2} \mathrm{~F}_{2}$. The same comfort levels may be reached in both old and new buildings. The expenditure required with present energy prices (dotted line) to reach a given comfort level in the old buildings, however, is greater than in the buildings with optimal thermal characteristics.

Increasing insulation levels in walls and ceilings results in substituting capital investment, and hence fixed costs, for variable cost, in the form of fuel bills. Once a house is purchased, the capital investment represents a fixed cost which affects the level of disposable income and the marginal cost of space conditioning. Consumer choice of comfort level will be influenced by the marginal cost of space conditioning and this may be considerably lower in an energy efficient building than in a standard one.

Following an increase in the relative price of energy, owners of structures embodying a technology which is no longer optimal may find themselves in disequilibrium. Their short term response may include changing the temperature maintained to consume less energy for space heating. This is shown in Figure 3 by the movement from comfort level 1 to comfort level 2. The original cost minimizing point for production of comfort level 1 , is shown at an energy consumption level of $F_{1}$. At the new higher energy price, point $F_{2}$ is optimal and owners of the old technology homes have responded by adjusting temperature and accepting a lower comfort leve 12 with fuel consumption $F_{3}$. At this point if they choose to spend exactly the same amount on space conditioning as owners of new homes, they consume more fuel but are less comfortable. This represents an equilibrium point for those individuals whose preferences have changed so that they value saving energy over being warm in winter or cool in sumer, and for those who can easily substitute behavioral strategies, such as wearing thermal underwear, for space heating. 


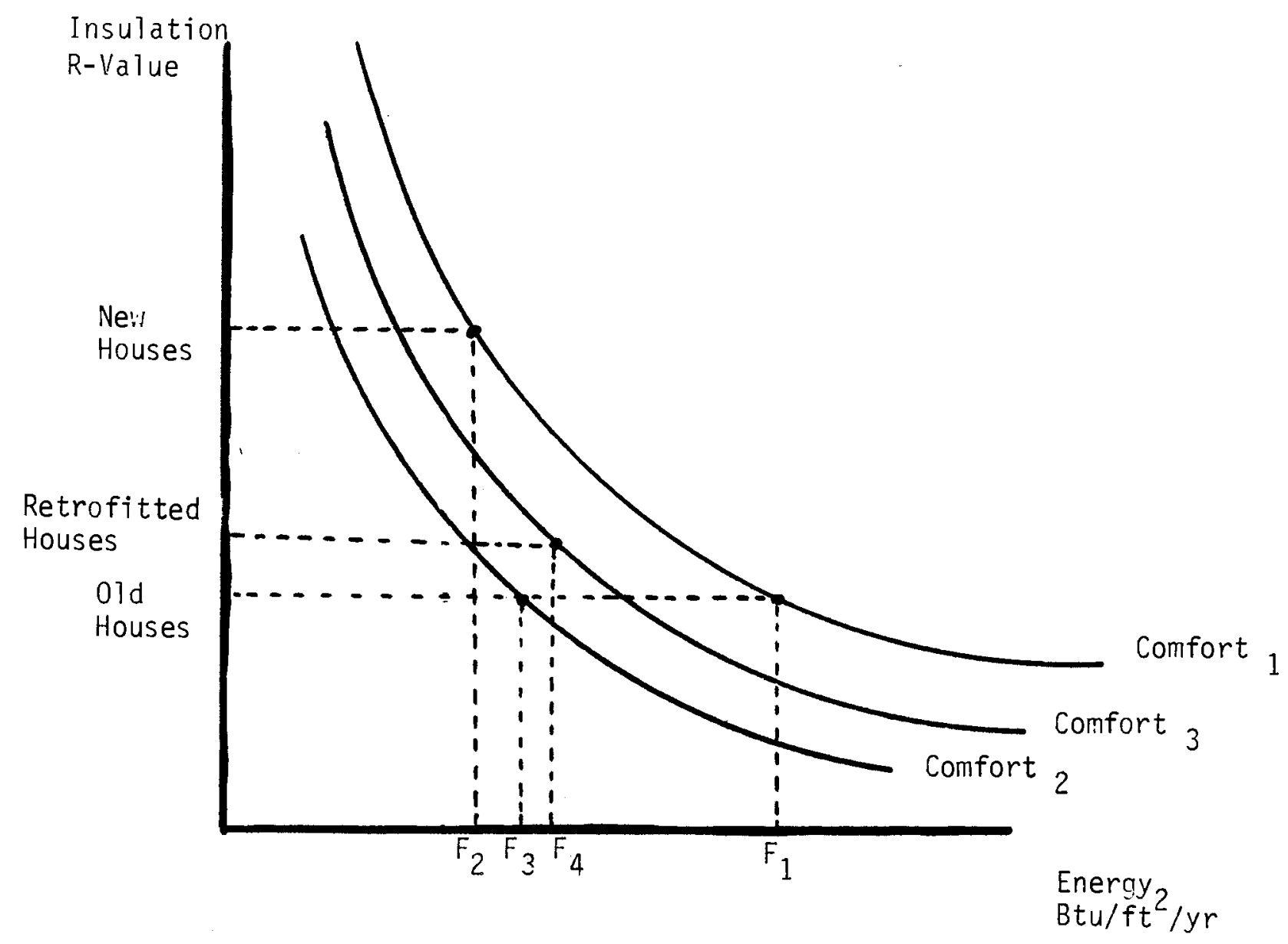

FIGURE 3. Response of Building Owners to Increased Real Energy Costs

For others, longer range alternatives include purchasing a new house or altering the old so that it approximates the cost minimizing technology. The effects of retrofitting an older home are also shown in Figure 3. Depending on the costs and energy efficiency of the retrofit options available to the owners of older homes, comfort leve 13 , reached by retrofitting, may lie anywhere between comfort levels 1 and 2. A wide range of resulting energy consumption levels, $F_{4}$, are possible depending on the effectiveness of the retrofit options chosen. It is likely, however, that it will cost more to retrofit an old house to use $F_{2}$ or less energy at comfort leve 11 than to incorporate the same energy conserving features in a new house. 
DATA COLLECTION

The final sample consists of complete and useable questionnaires with associated electricity and climate data for 35 households. Eighteen of the respondents were in the old subdivision and 17 in the new. Two survey instruments (one for each subdivision) were developed to collect information from occupants. The desired information included physical changes made in the houses, household demographic characteristics, and occupants' attitudes and behaviors related to energy use. Permission for release of billing data by the utilities was obtained from respondents at the time they completed a questionnaire.

The resulting data items are sumarized in Table 1. They fall within four categories: construction characteristics; electricity use; climatological data; and occupant characteristics. The first of these includes information about the physical characteristics of the structures, such as levels of insulation in walls or ceiling, and total square footage. Billing data from the utilities include physical quantities, billing periods and prices. Because the efficiencies of energy use for heating and cooling differ, the consumption data periods were divided into separate, non-overlapping, heating and cooling seasons. Disparities in billing dates and billing periods were also taken into account. The climatological category incorporated data on heating and cooling degree days obtained from the Hanford weather station. Data under occupant characteristics included sociodemographic variables such as household income, race and family size; attitudes concerning energy issues and purchase decisions; and energy related behaviors, including appliance ownership, thermostat settings and conservation activities.

\section{VARIABLE FORMULATION}

The data used in this portion of the analysis include home construction and occupant characteristics, climatic variation, electricity consumption and cost. Variable definitions, billing data standardization, and scale construction are discussed below. 
TABLE 1. Sources and Types of Energy Consumption Related Data

Data

Construction Characteristics

Floor Plan

Floor area

Building type

Construction techniques

Electricity Use Cons umption

Price

Climato logical Data

Heating degree days

Cooling degree days

Occupant Characteristics

Demographic:

Household size

Education

Income

Employment

Attitudina 1:

House purchase decision factors

Importance of Price

Energy supply expansion

Coping behavior

Behavioral:

Thermostat settings

Energy aud it

Conservation activities

Appliance ownership

Conservation retrofits
Sources

Builder

Utilities

Hanford Climatological Station

Occupants 


\section{Construction Characteristics}

Information on construction characteristics of the residences allowed computation of the $R$ values of the insulation at the time of construction. Floor areas ranged from 1008 to 2000 square feet. The average size was larger in the new subdivisions than in the old. Houses were either ranch style, trilevel or two story (including split entry) models.

Cl imatological Data

Heating and cooling degree day data were obtained from the Hanford Climatological Station, where such data are regularly computed from systematically maintained temperature records. Heating and cooling degree days do not represent the complete range of climatological phenomena which impinge on the built environment. They are, however, used as a proxy for other climatic conditions. Electricity Use

Two variables are considered in analyzing electricity consumption. These are the the average price per kilowatt hour and the quantity consumed. In this study inclusion of a residence in a particular subdivision serves as a surrogate for price. The price per kilowatt hour in the old subdivision is twice that in the new ( $\$ .032$ and $\$ .017$ per kilowatt hour, respectively). The consumption measure obtained from utility bills is total kilowatt hours consumed in a given period. In studies using data from much larger samples, this is usually adequate since the researcher may control for (i.e., hold constant) such variables as size of house (square footage) and heating degree days. With the small sample available for this study, the application of such statistical controls is infeasible. The most appropriate alternative is to normalize the energy consumption measure in a manner that provides comparability across consumption units regardless of size or climate. This is accomplished by first limiting observations to the one heating season for which complete data are available for all units. Secondly, the total kilowatt hours consumed by each unit is multiplied by 3,412 to obtain a measure of total Btu consumption. The number thus obtained is divided by the number of heating degree days and then by the total area $\left(\mathrm{ft}^{2}\right)$ of the respective residential unit. The measure of consumption thus derived is the number of Btu per heating 
degree days per $\mathrm{ft}^{2}$. We assume a virtual absence of measurement error in this variable, since the kilowatt hour consumption is obtained from utility billing records, floor area from builder's design information and heating degree days from the Hanford Climatological Station.

\section{Occupant Characteristics}

Three categories of occupant characteristics are of concern in this analysis. These include demograhic, attitudinal and behavioral factors. Variables within each area and the manner in which they were operationalized are as follows:

- Demographic Factors:

1. Household size. This item was measured as the total number of occupants.

2. Age structure of household. Information was requested on the number of adults and children in each of several age categories.

3. Education. The number of years of formal education completed by the respondent and respondent's spouse. Because it was unknown whether the husband or the wife was the respondent, these totals were added together and divided by two to obtain an average household educational level.

4. Income. Seven income categories were used in order to minimize non-response. These ranged from less than $\$ 10,000$ to more than $\$ 60,000$, in $\$ 10,000$ increments. The categories reflected the range of gross total family income.

5. Employment. This item did not differentiate between occupational statuses, but rather provided the number of occupants employed outside the home, and whether they were employed full or part time. Use of this measure is based on the expectation that less energy is consumed in an empty house than in one that is occupied.

6. Race. Respondents were requested to indicate their race. Choices available included the usual designations: Caucasian (white); Black, Oriental, Spanish American, Native American, and other. 
7. Home Ownership. An attempt was made to differentiate between home owners and renters.

- Attitudinal Factors. An initial attempt was made to formulate a scale that would reflect respondents' attitudes toward energy policy issues. Ten items were developed to tap various dimensions, such as attitudes toward expansion of supply, reduction of demand and changes in life style. Respondents were asked to indicate the degree to which they favored or opposed various strategies. The strategies included: "rationing fuel"; "accelerating coal production"; "raising fuel prices to curb demand".

The attitudinal items may represent the weakest part of the survey. As a result of limited funds and initial time constraints, it was not possible to build an attitudinal scale through the usually recommended and desirable procedures of item creation, discriminant analysis, item selection and factor analysis. Instead items were chosen that had been used in prior studies or that appeared to the authors and their colleagues to be face valid and intuitively acceptable. To paraphrase an old maxim, one may of ten "scale in haste and repent at leisure."

Given initial indication that the policy scale items selected were anything but unidimensional, a factor analysis of the items was undertaken, in spite of the limited sample size. While no definitive results were expected, the initial factor analys is suggested that there were three $f$ actors and that the tenth item was inappropriate. It had a factor loading of over 1.0 indicating a high probability of linear interdependence with other items. Item 10 was removed, the factors were limited to three and the analysis repeated. For the nine items which remained, there were three items with moderate to high loadings on each of three factors. The first factor appeared to reflect concern with energy price or cost and is referred to as the PRICE SUBSCALE. The second factor, SUPPLY EXPANSION SUBSCALE, contained three items referring to the expansion 
of energy supply through new coal, oil and gas, and nuclear production. The third factor, COPING SUBSCALE, seemed to reflect shortterm coping behavior and incorporated notions of lifestyle change. The policy scale items were obviously not unidimensional in nature and more work with a larger sample would almost certainly prove helpful. That the supply expansion subscale proved a predictor of behavior in at least one instance is promising for further testing of the attitude-behavior relationship in energy consumption.

In addition to the attitude scales, respondents were asked to indicate the severity of energy shortages in the U.S. Responses included "major", "moderate" and "no problem."

- Behavioral Factors. The behavioral factors attempted to measure the amount of conservation activity practiced by respondents. The conservation behaviors of concern included:

1. Winter and sumer thermostat settings.

2. Water heater temperature setting.

3. Whether or not the respondent had received an energy audit.

4. The number and kind of appliances used in the household.

5. The number and nature of conservation retrofits. This included such behavior as adding insulation, or storm windows.

6. Behavioral conservation activities, including turning off lights, closing drapes at night, changing furnace filters and flushing out hot water heaters.

7. General Conservation Activities. This question asked, "Which of the following have you done in the last 3 years to reduce utility bills or energy consumption?," and included such items as reducing travel, riding bicycles, and using carpools. The idea was to determine whether or not a general conservation ethic was present and if so, the degree to which it was related to household energy conserving behavior. 


\section{DATA PRESENTATION AND ANALYSIS}

This section consists of three main parts. Descriptive statistics of interest for the total sample are presented in the first part. The second part compares the old and new subdivision groupings within the sample and explores their similarities and significant dissimilarities. The third part deals with the relationships between the independent and dependent variables and among key independent variables.

\section{Data Summary}

The descriptive statistics presented in this section are for major variables or indices created in the course of the analysis. This discussion of the data does not attempt to be comprehensive but rather to provide the most relevant pieces of information regarding the types of homes and households involved in this study. Table 2 shows statistics for the entire sample, starting with physical characteristics of the homes and measures of their electricity consumption. Then demographic, attitudinal and finally, behavioral characteristics of the occupants are presented.

Houses included in the study are relatively small, with a median size of $1264 \mathrm{ft}^{2}$. Only four of the houses contain more than $1400 \mathrm{ft}^{2}$. In spite of the relative homogeneity in size, their range of electricity consumption during the heating season is such that the highest observation of Btu per heating degree day is four times the lowest. Standardizing this data for house size (Btu/HDD/ft ${ }^{2}$ ) only slightly reduces the magnitude of the range.

Generally the houses are occupied by from two to four people, the average being just under three. The adults have had some college education and the mean gross family income is over $\$ 30,000$ a year.

The attitudinal items are only briefly identified in Table 4.1. Actual wording of the items can be found in the questionnaires (appendix). While responses covered the full range of possibilities on most items, there was a consensus that energy shortages are an important, if not major, problem. The responses to the ten energy policy related items indicated support for all types of energy supply expansion except fuel importation. There was general 
TABLE 2. Descriptive Statistics for the Total Sample

\begin{tabular}{|c|c|c|c|c|c|}
\hline \multirow[b]{2}{*}{ Variables } & \multicolumn{2}{|c|}{ Range } & \multirow[b]{2}{*}{ Median } & \multirow[b]{2}{*}{ Mean } & \multirow{2}{*}{$\begin{array}{l}\text { Standard } \\
\text { Deviation }\end{array}$} \\
\hline & Min & Max & & & \\
\hline $\begin{array}{l}\text { Square Footage } \\
\text { Appli ances }\end{array}$ & $\begin{array}{r}1008 \\
4\end{array}$ & $\begin{array}{r}2000 \\
8\end{array}$ & $\begin{array}{r}1264 \\
6.10\end{array}$ & $\begin{array}{r}1236.97 \\
.9\end{array}$ & 215 \\
\hline $\begin{array}{l}\text { Electricity Consumption } \\
\text { BTU/HDD } \\
\text { BTU/HDD/FT } 2\end{array}$ & $\begin{array}{r}3840 \\
3.81\end{array}$ & $\begin{array}{l}16064 \\
13.35\end{array}$ & $\begin{array}{l}9571 \\
7.32\end{array}$ & $\begin{array}{r}9453 \\
7.67\end{array}$ & $\begin{array}{r}3112 \\
2.38\end{array}$ \\
\hline
\end{tabular}

\section{Occupant Characteristics}

Demographic:

Total Occupants

Education

Income

$\begin{array}{rrrrr}1 & 5 & 2.96 & 2.97 & 1.10 \\ 9 & 20 & 13.82 & 13.77 & 2.15 \\ 1 & 4 & 3.21 & 3.16 & .81\end{array}$

Attitudinal:

$\begin{array}{llllll}\text { Energy shortage(a) } & 1 & 2 & 1.18 & 1.27 & .45 \\ \text { Lower prices(b) } & 1 & 5 & 3.44 & 3.49 & 1.42 \\ \text { Raise prices(b) } & 1 & 5 & 3.00 & 3.62 & 1.50 \\ \text { Efficiency standards(b) } & 1 & 5 & 1.13 & 1.44 & .96 \\ \text { Expand nuclear(b) } & 1 & 5 & 1.35 & 1.97 & 1.40 \\ \text { Expand coal(b) } & 1 & 5 & 1.40 & 1.91 & 1.26 \\ \text { Expand oil and gas(b) } & 1 & 5 & 1.35 & 1.68 & .98 \\ \text { Import more ffel(b) } & 1 & 5 & 4.61 & 4.21 & 1.12 \\ \text { Ration fue (b) } & 1 & 5 & 3.50 & 3.44 & 1.46 \\ \text { Change life style(b) } & 1 & 5 & 1.88 & 2.03 & 1.03 \\ \text { subsidize conservation(b) } & 1 & 5 & 2.10 & 2.59 & 1.67\end{array}$

Behavioral:

Building Conservation

Activities
General Conservation

Activities

$\begin{array}{rrrll}3 & 10 & 6.92 & 6.6 & 1.72 \\ 1 & 9 & 5.19 & 5.37 & 2.10\end{array}$

Thermostat Settings:

Winter Day

Winter Night

Surmer

$\begin{array}{rrrrr}60 & 75 & 68.63 & 67.12 & 4.11 \\ 50 & 72 & 64.65 & 63.12 & 4.94 \\ 68 & 85 & 75.14 & 75.55 & 4.81 \\ & & & & \\ 1 & 3 & 1.86 & 1.82 & .59\end{array}$

Water Heater Temperature

$\begin{array}{ll}\text { (a) } 1=\text { major problem } & 2=\text { moderately important problem } \\ \text { (b) } 1=\text { favor } & 5=\text { opposed }\end{array}$ 
opposition to fue 1 rationing and to any manipulation of fue 1 prices. Support was indicated for changing lifestyle to save energy and to a lesser extent for subsidization of conservation investment. Thus both energy supply expansion and energy conservation were favored.

Respondents indicated that they take a variety of actions to save energy. In their homes the mean number of activities carried out frequently is 6.6 out of a possible 12 actions covered by the questionnaire. Most respondents also indicated they are doing a number of general things to reduce energy consumption, such as carpooling, reducing vacation travel, reducing hot water usage, etc.

Temperature settings chosen in these homes are, on average, relatively energy conserving. However, the minimum winter day and night settings probably do not reflect actual indoor temperature due to use of wood for heating. The average water heater temperature reported is less than $140^{\circ}$, which is lower than generally recommended.

Group Comparisons

Comparison of residential units in the old and new subdivisions begins with an examination of variables in the demographic category. Because of the similarity across subdivisions in house design characteristics unrelated to energy efficiency, the appropriate hypothes is to be tested is the null hypothesis of no difference between groups. Given the small sample size, the t test for differences between means was employed. The null hypothes is of the form

was tested against the alternative

$$
H_{0}: \bar{x}_{\text {old }}=\bar{x}_{\text {new }}
$$$$
H_{\mathrm{a}}: \bar{X}_{\text {old }} \neq \bar{x}_{\text {new }}
$$

Table 3 presents the variable name, mean, and standard deviation of the major demographic variables for each subdivision grouping. The two right hand columns present the computed $t$ statistic for the means test and the level of statistical significance. Given the exploratory nature (due largely to sample 
TABLE 3. Comparison of Demographic Characteristics

Across Subdivisions

\begin{tabular}{|c|c|c|c|c|c|}
\hline Variable & Subdivision & Mean & $\begin{array}{l}\text { Standard } \\
\text { Deviation }\end{array}$ & $\mathrm{t}$ & $\begin{array}{c}\text { 2-Tailed } \\
\text { Probability }\end{array}$ \\
\hline Total occupants & $\begin{array}{l}\text { Old } \\
\text { New }\end{array}$ & $\begin{array}{l}2.83 \\
2.76\end{array}$ & $\begin{array}{l}1.30 \\
1.30\end{array}$ & 0.16 & 0.88 \\
\hline $\begin{array}{l}\text { Age Structure: } \\
\text { Number of Minors }\end{array}$ & $\begin{array}{l}\text { Old } \\
\text { New }\end{array}$ & $\begin{array}{l}0.78 \\
1.00\end{array}$ & $\begin{array}{l}1.11 \\
0.94\end{array}$ & -0.64 & 0.53 \\
\hline Number of Adults & $\begin{array}{l}\text { 0ld } \\
\text { New }\end{array}$ & $\begin{array}{l}2.18 \\
1.88\end{array}$ & $\begin{array}{l}0.53 \\
0.34\end{array}$ & 1.96 & 0.06 \\
\hline Education & $\begin{array}{l}\text { 01d } \\
\text { New }\end{array}$ & $\begin{array}{l}13.56 \\
14.00\end{array}$ & $\begin{array}{l}2.70 \\
1.35\end{array}$ & -0.55 & .59 \\
\hline Income (a) & $\begin{array}{l}\text { 01d } \\
\text { New }\end{array}$ & $\begin{array}{l}2.82 \\
3.53\end{array}$ & $\begin{array}{l}0.81 \\
0.64\end{array}$ & -2.73 & 0.01 \\
\hline
\end{tabular}

(a) Income category $2=\$ 10,000-20,000,3=\$ 20,000-30,000,4=$ $\$ 30,000-40,000$

size) of this study, the .1 level was selected as the criterion level for the rejection of the nu 11 hypothes is and affirmation of the alternative. Because an $F$ test supported the hypothesis of equal variance across subdivision samples, a pooled variance $t$ test was employed.

As indicated in Table 3, the demographic characteristics of occupants do not differ systematically between the old and new subdivisions. One of the two areas of significant difference is in the population age structure. There are higher percentages of households with young children in the new subdivisions and with three adults in the old subdivision. The other highly significant difference is that mean income is 25 percent higher in the new subdivisions than in the old. This difference is critical from a theoretical perspective, in that households with higher incomes are expected to consume more energy. Several demographic characteristics were so consistent across subdivisions that a means test was not performed. Identical percentages of adult household 
members were employed full-time and part-time. All of the residents owned their homes and virtually all were the first owner. In addition, almost all of the residents were Caucasian.

Energy-related attitudes of the building occupants were ascertained using several different measures. On a question regarding perception of energy shortages, over $70 \%$ indicated they consider energy shortages a major problem and none considered shortages nonexistent or no problem. There was virtually no difference in response distribution across groups. This was also true of responses to the ten energy policy items discussed in conjunction with Table 2 . A means test on these policy items showed a significant difference between the old and new subdivisions on only one item, acceleration of nuclear energy production. New subdivision occupants are more supportive of nuclear energy $\left(\bar{X}_{\text {new }}=1.4, \bar{X}_{\text {old }}=2.6, t=2.83, p=0.008\right)$.

The comparison of behavioral characteristics across subdivisions, shown in Table 4, covers appliance ownership, household activities to conserve energy and thermostat settings used in the home. While no measure of relative appliance energy use is available, there is no difference between the subdivisions in the number of major appliances owned. Differences were not apparent in the number of strategies, such as closing heat vents and turning off lights, used to conserve energy in the houses. The number of general energy conserving actions taken, including participation in carpools, also differed little across the subdivisions.

Some important behavioral differences were apparent in the thermostat settings chosen by occupants of the two sets of houses. Though only winter night temperature differs significantly, the direction of difference is consistent for the four variables. As can be seen at the top of Table 4, the mean water heater, winter day and winter night temperature settings are higher and the summer temperature lower in the new subdivision than in the old. As a result one would expect to find higner levels of energy consumption in the new subdivision than in the old. The fact that the winter night temperature setting in the new subdivision is significantly higher is important since more energy is used in maintaining indoor temperatures at night than in the daytime when the indoor/outdoor temperature differential is usually smaller. 


\section{TABLE 4. Comparison of Behavioral Characteristics}

Across Subdivisions

\begin{tabular}{|c|c|c|c|c|c|}
\hline Variable & Subdivision & Mean & $\begin{array}{l}\text { Standard } \\
\text { Deviation }\end{array}$ & $t$ & $\begin{array}{l}\text { 2-Tailed } \\
\text { Probability } \\
\end{array}$ \\
\hline $\begin{array}{l}\text { Winter Day } \\
\text { Temperature }\end{array}$ & $\begin{array}{l}\text { 01d } \\
\text { New }\end{array}$ & $\begin{array}{l}66.35 \\
67.94\end{array}$ & $\begin{array}{l}4.23 \\
3.96\end{array}$ & -1.11 & 0.28 \\
\hline $\begin{array}{l}\text { Winter Night } \\
\text { Temperature }\end{array}$ & $\begin{array}{l}\text { 01d } \\
\text { New }\end{array}$ & $\begin{array}{l}61.53 \\
64.81\end{array}$ & $\begin{array}{l}4.36 \\
5.08\end{array}$ & -1.99 & 0.06 \\
\hline Surmer Temperature & $\begin{array}{l}\text { 01d } \\
\text { New }\end{array}$ & $\begin{array}{l}75.94 \\
75.13\end{array}$ & $\begin{array}{l}5.31 \\
4.35\end{array}$ & 0.48 & 0.63 \\
\hline Winter Temperature(a) & $\begin{array}{l}\text { 01d } \\
\text { New }\end{array}$ & $\begin{array}{l}1.75 \\
1.90\end{array}$ & $\begin{array}{l}0.45 \\
0.74\end{array}$ & -.59 & .56 \\
\hline Number of Appliances & $\begin{array}{l}\text { 01d } \\
\text { New }\end{array}$ & $\begin{array}{l}6.22 \\
5.88\end{array}$ & $\begin{array}{l}0.94 \\
0.99\end{array}$ & 1.04 & 0.31 \\
\hline $\begin{array}{l}\text { Building Conservation } \\
\text { Activities Scale }\end{array}$ & $\begin{array}{l}\text { 01d } \\
\text { New }\end{array}$ & $\begin{array}{l}6.72 \\
6.47\end{array}$ & $\begin{array}{l}1.87 \\
1.49\end{array}$ & .43 & .67 \\
\hline $\begin{array}{l}\text { Energy Conserving } \\
\text { Activities }\end{array}$ & $\begin{array}{l}\text { 0ld } \\
\text { New }\end{array}$ & $\begin{array}{l}5.61 \\
5.12\end{array}$ & $\begin{array}{l}2.38 \\
1.80\end{array}$ & 0.69 & 0.49 \\
\hline
\end{tabular}

(a) Category $1=120^{\circ}, 2=140^{\circ}$.

Information on behavioral characteristics such as obtaining an "energy audit" and investing in retrofit options for energy conservation was only collected for the old subdivision. It was found that one third of those households had an energy audit performed. The reported frequency of installation or intended installation in 1980 of various retrofit options is shown in Table 5. the most common retrofit measure is installation of a wood-burning stove, which had been done in half of the homes. The next most common activities are weatherstripping and installation of storm windows. For the 18 homes in this sample, the mean number of retrofit options installed is 2.67 , with $28 \%$ doing five or six. 
TABLE 5. Percentage of 0ld Subdivision Houses With Various Retrofit Options

Percentage

Option

Ceiling Insulation

Wall Insulation

Weatherstripping

Storm Windows

Storm Doors

Window Caulking

Night Set-Back Thermos tat

Attic Fan

Humidifier

Fireplace Doors

Solar Water Heater

Woodburning Stove

Water Heater Insulation
Installed or Intended Actually Installed

39

22

55

50

44

50

17

11

11

33

0

50

61
17

17

39

44

11

17

11

6

11

28

0

50

11

An additional group comparison was carried out for homes in the old subdivision with and without woodstoves. Attitudinal and demographic characteristics did not differ significantly between these groups. Means tests on the thermostat settings for both groups are presented in Table 6 . These settings are of interest because of their direct relationship to electric energy consumption. While only the differences in summer temperature and water temperature are significant, all of the differences are consistently in the direction of less electricity use by those with woodstoves than by those without them. In addition, the difference in winter day temperature settings approaches significance. The relatively high summer temperature chosen by the woodstove group is particularly interesting because it is unrelated to heating and may indicate different temperature preferences or home use patterns between the two groups.

Energy use in the old and new subdivisions was compared (Table 7) on the bas is of electricity consumption per heating degree day per square foot (Btu/ $\mathrm{HDD} / \mathrm{ft}^{2}$ ). Because of the construction dates of the new houses, there were insufficient data available to analyze energy use for cooling. The analys is also is limited because the measure of heating energy consumption used has 
TABLE 6. Comparison of Temperature Settings Within the 01d Subdivision

\begin{tabular}{|c|c|c|c|c|c|}
\hline Variable & Woodstoves & Mean & $\begin{array}{l}\text { Standard } \\
\text { Deviation }\end{array}$ & $t$ & $\begin{array}{c}2-T a i l e d \\
\text { Probability } \\
\end{array}$ \\
\hline $\begin{array}{l}\text { Winter Day } \\
\text { Temperature }\end{array}$ & $\begin{array}{l}\text { With } \\
\text { Without }\end{array}$ & $\begin{array}{l}64.63 \\
67.89\end{array}$ & $\begin{array}{l}3.93 \\
4.08\end{array}$ & -1.68 & 0.11 \\
\hline $\begin{array}{l}\text { Winter Night } \\
\text { Temperature }\end{array}$ & $\begin{array}{l}\text { With } \\
\text { Without }\end{array}$ & $\begin{array}{l}60.25 \\
62.67\end{array}$ & $\begin{array}{l}4.68 \\
3.97\end{array}$ & -1.15 & 0.27 \\
\hline Summer Temperature & $\begin{array}{l}\text { With } \\
\text { Without }\end{array}$ & $\begin{array}{l}78.89 \\
73.33\end{array}$ & $\begin{array}{l}5.52 \\
3.67\end{array}$ & 2.47 & 0.03 \\
\hline Water Temperature(a) & $\begin{array}{l}\text { With } \\
\text { Without }\end{array}$ & $\begin{array}{l}1.57 \\
2.00\end{array}$ & $\begin{array}{l}0.54 \\
0.00\end{array}$ & 2.12 & 0.08 \\
\hline
\end{tabular}

(a) Category $1=120^{\circ}, 2=140^{\circ}$.

two major shortcomings. First, all of the homes in the new subdivision and most homes in the old had fireplaces, woodstoves, or both. As a result, their actual heating energy consumption is probably a combination of measured Btu of electricity and unmeasured Btu of wood. Second, many of the homes were originally built with unheated and uninsulated garages. Information was not obtained regarding conversion of such space to living area so electricity consumption is measured in relation to designed living area.

TABLE 7. Comparison of Electricity Consumption for Heating Across Subdivisions

\begin{tabular}{|c|c|c|c|c|c|}
\hline Variable & Groups & Mean & $\begin{array}{l}\text { Standard } \\
\text { Deviation }\end{array}$ & $t$ & $\begin{array}{c}2-T a i l e d \\
\text { Probability } \\
\end{array}$ \\
\hline $\mathrm{Btu} / \mathrm{HDD} / \mathrm{ft}^{2}$ & $\begin{array}{l}\text { 0ld } \\
\text { New }\end{array}$ & $\begin{array}{l}7.09 \\
8.28\end{array}$ & $\begin{array}{l}2.13 \\
2.53\end{array}$ & -1.51 & 0.14 \\
\hline $\mathrm{Btu} / \mathrm{HDD} / \mathrm{ft}^{2}$ & $\begin{array}{l}\text { 01d-Wood- } \\
\text { stoves } \\
\text { old-No } \\
\text { stoves }\end{array}$ & $\begin{array}{l}5.80 \\
8.38\end{array}$ & $\begin{array}{l}1.55 \\
1.88\end{array}$ & -3.17 & 0.01 \\
\hline
\end{tabular}


These $f l$ aws in the measurement of energy consumption, tend to understate total energy use per $\mathrm{ft}^{2}$ in homes with woodstoves in the old subdivision and overstate it in the old subdivision homes with converted garages. In spite of this, the mean electricity consumption in the new homes is higher than in the old and the difference is almost significant. When differences in electricity consumption are compared between homes with and without woodstoves in the old subdivision, the Btu consumption of those with woodstoves is significantly lower $(p \leq .01)$. There are an equal number of cases in each group. Variable Relationships

There are several reasons why it is desirable to examine the bivariate relationships between varibles of interest in this study. First, since the sample size is small $(N=35)$, a multiple regression analysis is at best, tenuous. Second, little is know about the influence of demographic, attitudinal and behavioral factors on energy consumption. As Blalock (1972, p. 361) states, "When interest is focused primarily on the exploratory task of finding out which varibles are related to a given variable, we are likely to be interested in measures of degree of relationships such as correlation coefficients."

To explore variable interrelationships the correlation coefficient $r$, the product-moment correlation, is an appropriate measure of association between variables. this coefficient measures, "the amount of spread about the linear least squares equation" (Blalock 1972, p. 376). In addition, $r$ has the advantage of being reasonably easily interpretable. It must be remembered that $r$ is a measure of a linear relationship. The coefficient, $r$, will range from -1.0 through 0 to +1.0 with unity being achieved cnly when all data points fall on a straight line. Random data points will result in a coefficient approximating zero. Briefly, $r$ relates to the relationship of the variation in $X$ and the variation in $Y$ where $X$ and $Y$ are the independent and dependant variables, respectively.

For bivariate correlation analysis the $F$ test is applied to test the statistical significance of the relationship. Use of the $F$ test addresses the likelihood of particular $r$ value occurring if, in fact, there were no linear association in the population. It should be noted that the computed $F$ value 
is a function of $r^{2}$ and sample size. As sample size increases the likelihood that a particular value of $r$ is significant also increases. Thus, a statistically significant $r$ value in a study with a sample size as small as used here is indicative that the relationship very probably is not artifactual.

The first step in examining the bivariate relationships utilized the entire sample and computed correlation coefficients for key variables in the demographic, attitudinal and behavioral categories. Table 8 lists, by category, the independent variables and presents the correlation coefficients between each variable and the dependent variable, electricity consumed, measured as Btu/heating degree day/ft ${ }^{2}$. Also presented are the mean $(X)$, standard deviation (S.D.) and level of significance ( $\alpha$ ).

Implicit in correlational analys is of the type discussed here is the testing of the null hypothesis $\left(H_{0}\right)$ of no linear relationship between variables against the alternative hypothesis $\left(H_{a}\right)$ of a significant, non-zero relationship. Notationally this may be represented as:

$$
\begin{aligned}
& H_{0}: \rho=\beta=0 \\
& H_{a}: \rho \neq \beta \neq 0
\end{aligned}
$$

As traditionally presented, the null and alternative hypotheses use the Greek symbols representing the population parameters. For the sample the appropriate symbols are $r$ and $b$ respectively. The values for $r$ and $b$ (and thus $\rho$ and $\beta$ ) are equatable. Since they have the same numerator, the test of the hypothesis $r=0$ is also a test of the hypothesis $b=0$.

As may be seen in Table 8, one of the three demographic variables related positively and significantly to the amount of energy consumed. For the total number of occupants, a positive and significant correlation is not unexpected. It indicates that as the number of occupants in a residence increases, the amount of energy used also increases. The relationship of family income to electricity consumption is not significant, possibly because of homogeneity in the sample. The relationship of education to consumption is also positive though not significant. 
TABLE 8. Zero Order Correlations $(r)$ of Btu/HDD/Ft ${ }^{2}$ with Selected Independent Variables

\begin{tabular}{|c|c|c|c|c|c|}
\hline \multicolumn{6}{|l|}{ Demographic Variables } \\
\hline Total Occupants & 0.38 & 0.02 & $\begin{array}{r}2.97 \\
13.77\end{array}$ & $\begin{array}{l}1.10 \\
2.15\end{array}$ & 33 \\
\hline Income $(b)$ & 0.20 & N.S. & -- & -- & 32 \\
\hline \multicolumn{6}{|l|}{ Attitudinal Variables } \\
\hline Shortage Perception & -0.06 & N.S. & 1.23 & 0.49 & 35 \\
\hline Price Scale & -0.04 & N.S. & 10.80 & 3.82 & 35 \\
\hline Supply Scale & -0.08 & N.S. & 6.17 & 4.38 & 35 \\
\hline Coping Scale & -0.04 & N.S. & 11.20 & 3.83 & 35 \\
\hline \multicolumn{6}{|l|}{ Behavioral Variables } \\
\hline Winter Day Temperature & 0.26 & 0.07 & 67.12 & 4.11 & 33 \\
\hline Winter Night Temperature & 0.01 & N.S. & 63.12 & 4.94 & 33 \\
\hline Water Temperature $(c)$ & -0.04 & N.S. & -- & -- & 22 \\
\hline Appliances & 0.05 & N.S. & 6.0 & 0.97 & 35 \\
\hline \multirow{3}{*}{$\begin{array}{l}\text { General Conservation } \\
\text { Activities } \\
\text { Building Conservation } \\
\text { Activities }\end{array}$} & & & & & \\
\hline & -0.12 & N.S. & 5.37 & 2.10 & 35 \\
\hline & -0.15 & N.S. & 6.6 & 1.72 & 35 \\
\hline & & & & & \\
\hline
\end{tabular}

(a) Criterion level of significance used throughout this study for rejection of $H_{0}$ is $\alpha=0.1$.

(b) Income was measured as a categorical variable. The $\bar{x}$ value fell between the $\$ 20,000$ and 30,000 categories.

(c) Water temperature was measured as a categorical variable. The $\bar{x}$ value fell between the $130^{\circ}$ and $140^{\circ}$ categories.

The behavioral variables attempted to assess positive actions on the part of respondents. Included in this category were thermostat settings for day and night use and hot water heaters. Of these, only the winter daytime thermostat setting was significantly related to heating season energy consumption. The number of appliances owned, general conservation activities engaged in and building conservation activities reported were not significantly associated with energy consumption.

In light of results from the previously conducted means tests, a similar correlation analys is was undertaken for each subdivision separately. Table 9 
TABLE 9. Zero Order Correlations of Btu/HDD/FT2 in the 01d Subdivision with Selected Independent Variables

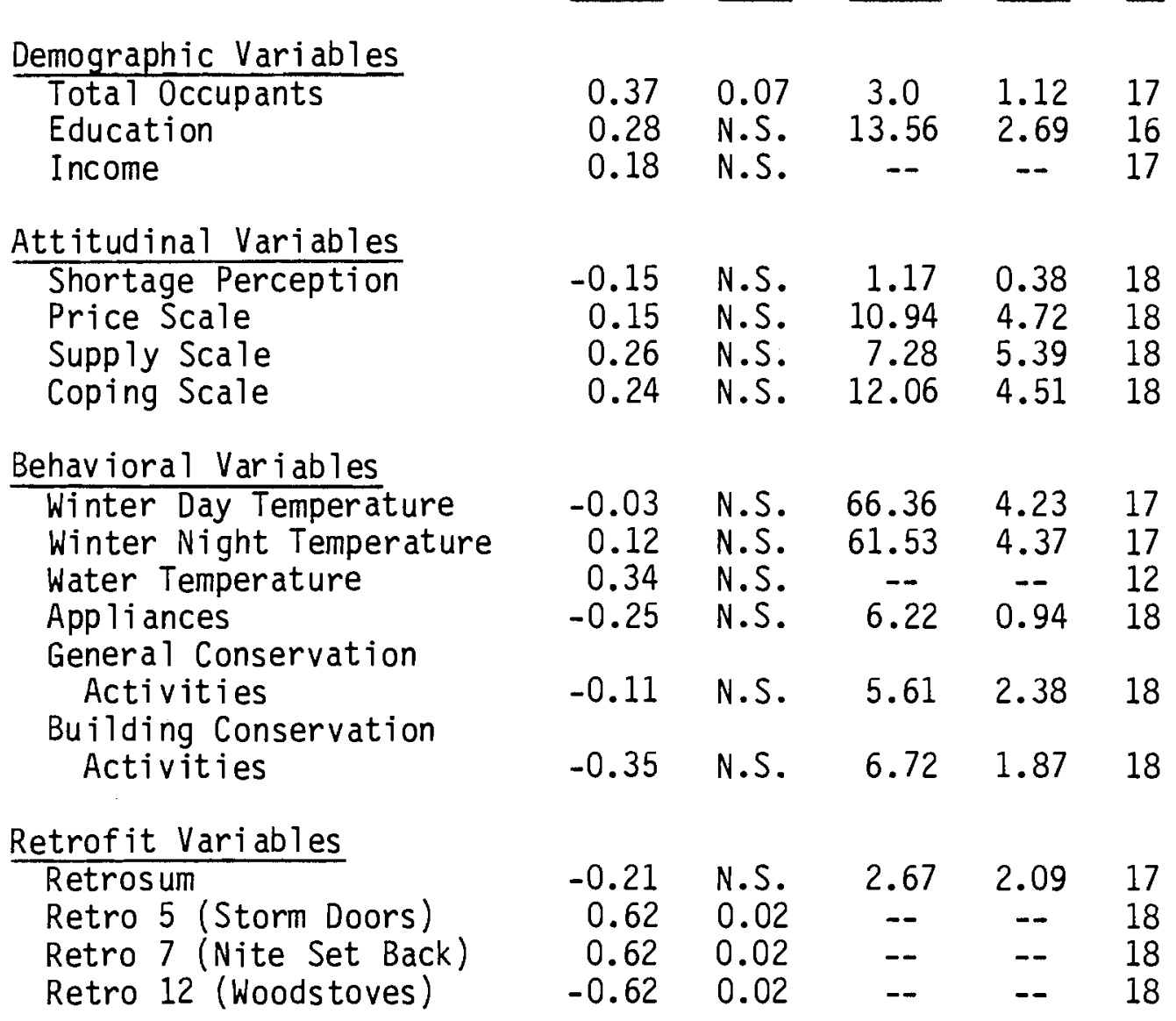

presents the zero order correlations sumarizing the relationships between energy consumption and selected independent variables in the old subdivision. The reader will note the addition of a new category of behavioral variables named Retrofit. Only residents of the old subdivision were questioned concerning retrofit behaviors. Fourteen retrofit options were included in the questionnaire and residents were asked to indicate which they had installed in the ir homes. A sumary variable, RETROSUM, was created by suming the number of retrofits a resident had installed. Among retrofits were such items as insulation, storm doors and windows, and woodstoves. The relationship of each of these retrofit options to electricity consumption was examined. Three were significant. The two positively related retrofit variables were storm doors 
and night set-back thermostats. These relationships are neither intuitive nor consistent with the theory presented earlier and may be an artifact of the small sample. The third significantly related retrofit variable was the presence of woodstoves which was significantly and negatively related to electricity consumption. That the retrofitting of woodstoves has had a clear and significant influence on electricity consumption is an interesting and potentially important finding in light of energy and environmental considerations. Often, woodstove use is thought of as a "counter culture" alternative. That there is a significant positive correlation between woodstove use and the supply expansion subscale $(r=0.33 p \leq 0.09)$ seems to indicate otherwise. Perhaps woodstoves are being viewed as part of an overall technological "fix". Users of woodstoves do, however, reportedly participate in more General Conservation Activities, in that the relationship between the two variables is also positive and significant $(r=0.41, p \leq 0.05)$. Unfortunately, the sample is not large enough to apply a statistical control technique such as a partial or multiple partial correlation which might have permitted more insight into wood stove use and characteristics of users. The only other significant relationships involving the woodstove retrofit were with winter day and night thermostat settings. This does not necessarily mean than woodstove users are experiencing a lower comfort level, but only that they are, in fact, substituting Btu from wood burning for electric heat. Further research into the nature of wood stove use, residential fuel switching in general and their potential impacts seems desirable.

An examination of Tables 9 and 10 indicates that of the demographic variables only the total number of occupants is significantly correlated with electricity consumption in both the old and new subdivisions. In the old subdivision education is negatively correlated with consumption at a nearly significant level $(r=-0.42, p \leq 0.11)$. since education and income are correlated for the total sample $(r=-0.31, p \leq 0.10)$ we can assume that some interaction is occuring between education and income which affects the consumption of electricity. It may well be that the homogeneity of the sample, vis a vis income, (after all, homes in both subdivisions are moderately priced) and the lack of variability in income, resulting from categorization of the 
TABLE 10. Zero Order Correlation of Btu/HDD/FT2 in the New

Subdivisions with Selected Independent Variables

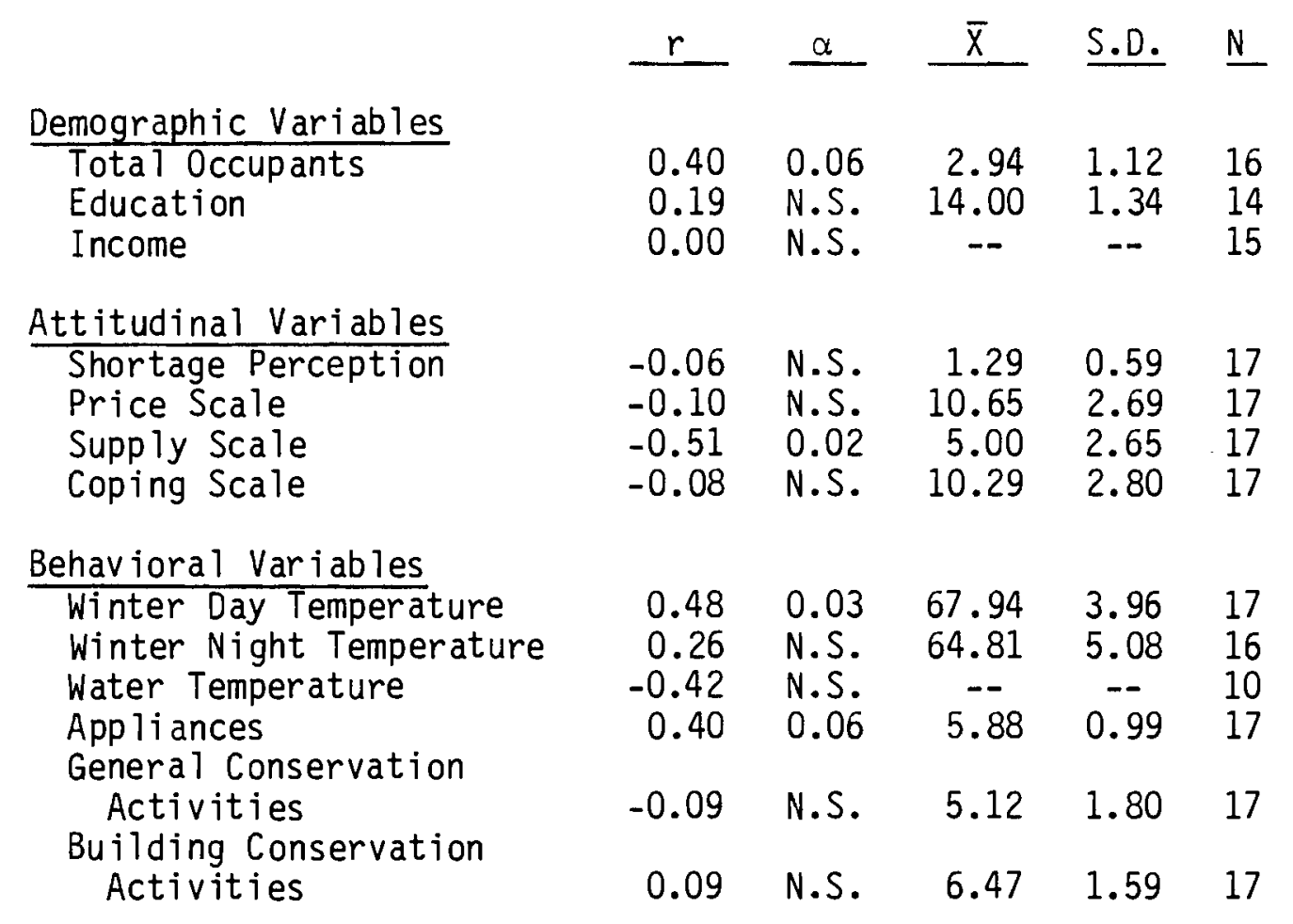

income variable, are acting to supress the actual relationship. A sample with greater variance in the income and education variables might well demonstrate the existence of a more clearcut relationship.

A further look at the income variable in the old subdivision indicates a significant, positive relationship between income and the sum of the installed retrofit options $(r=0.41, p \leq 0.05)$. This, coupled with a negative and significant relationship between retrosum and total occupants $(r=-0.45, p \leq 0.04)$ seems to indicate that greater availability of disposable income may increase the number of retrofit options installed.

An examination of the relationship between attitudinal variables and electricity consumption indicates no significant influence of attitudes on energy consumption when the sample is taken as a whole (Table 8 ). The absence of a relationship holds for respondents' perception of the severity of the 
energy shortage as well as attitudes reflected in the policy subscales (price related, supply expansion, and coping behavior). When examining the subdivisions separately (Tables 9 and 10) the magnitude of the relationship increases slightly but remains nonsignificant in all but one case. In In the new subdivision a statistically significant relationship emerges between energy consumption and the supply expansion subscale. This suggests that the more a respondent favors expansion of energy supplies (coal, oil or nuclear) the higher will be his energy consumption. Relationships between attitudinal variables and other independent variables indicate that attitudes may coincide with intermediate behavior that influences electricity consumption indirectly. Table 11 presents the zero order correlation for the attitudinal variables and the independent variables of concern. The relationships between income and perception of the energy shortage in the U.S. are positive and significant in the old subdivision. The same variables only approach significance in the new subdivision, but the direction is the same. In the old subdivision the less severe a respondent perceives the energy $\mathrm{cr}$ isis to be, the more appliances he is likely to own. In the new subdivision shortage perception is significantly related to the number of general conservation activities reported.

The price subscale relating to the cost of energy is not significantly related to any of the independent variables (except negatively to education in the new subdivision $p \leq .1$ ) nor the dependent variable and, for all practical purposes, can be eliminated from consideration. The supply expansion subscale is positively related to winter night temperature settings, significantly so in the older subdivision. The relationship of the supply scale to the number of general conservation activities reported approaches significance in the older subdivision and is significant at the .05 leve 1 in the new. Thus, the support for supply expansion is associated with lack of conservation oriented action. For the new subdivision a significant negative relationship occurs between the supply scale, and appliance ownership. The reason for this is unclear. There is also a positive relationship with water temperature in the new subdivision $(p \leq .1)$. 
TABLE 11. Zero Order Correlations Between Attitudinal Variables and Selected Other Independent Variables

\begin{tabular}{|c|c|c|c|c|}
\hline \multirow{2}{*}{ Variables } & \multicolumn{2}{|c|}{ old Subdivision } & \multirow[b]{2}{*}{ Supply Scale } & \multirow[b]{2}{*}{ Coping Scale } \\
\hline & $\begin{array}{c}\text { Shortage } \\
\text { Perception } \\
\end{array}$ & Price Scale & & \\
\hline Total Occupants & -0.17 & 0.01 & 0.03 & -0.10 \\
\hline Education & -0.12 & 0.31 & 6.02 & 0.33 \\
\hline Income & $0.38(p \leq .07)$ & 0.07 & 0.02 & 0.17 \\
\hline Winter Day Temperature & -0.07 & 0.01 & 0.29 & 0.02 \\
\hline Winter Night Temperature & -0.09 & 0.12 & $0.36(p \leq .08)$ & 0.26 \\
\hline Water Temperature & .17 & -0.44 & 0.08 & -0.02 \\
\hline Appli ances & $-0.38(p \leq .06)$ & -0.22 & -0.15 & -0.09 \\
\hline $\begin{array}{l}\text { Genera } 1 \text { Conservation } \\
\text { Activities }\end{array}$ & 0.05 & 0.06 & -0.30 & -0.21 \\
\hline $\begin{array}{l}\text { Building Conservation } \\
\text { Activities }\end{array}$ & -0.18 & $\begin{array}{l}-0.07 \\
\text { Subdivision } \\
\end{array}$ & -0.00 & -0.34 \\
\hline Total Occupants & -0.03 & -0.18 & -0.03 & 0.01 \\
\hline Education & 0.37 & $-0.45(p \leq .1)$ & 0.07 & $-0.87(p \leq .001)$ \\
\hline Income & 0.32 & 0.19 & -0.19 & 0.08 \\
\hline Winter Day Temperature & 0.14 & -0.03 & -0.02 & -0.20 \\
\hline Winter Night Temperature & -0.25 & 0.09 & 0.27 & -0.27 \\
\hline Water Temperature & -0.22 & 0.24 & 0.54 & 0.34 \\
\hline Appli ances & 0.15 & -0.30 & $-0.48(p \leq .03)$ & $-0.35(p \leq .09)$ \\
\hline $\begin{array}{l}\text { General Conservation } \\
\text { Activities }\end{array}$ & $0.33(p \leq .1)$ & -0.00 & $-0.43(p \leq .05)$ & 0.20 \\
\hline $\begin{array}{l}\text { Building Conservation } \\
\text { Activities }\end{array}$ & -0.12 & 0.20 & -0.03 & -0.23 \\
\hline
\end{tabular}


The last of the subscales, dealing with attitudes toward short to mid-term coping strategies such as fuel rationing, foreign imports or lifestyle changes, is not significantly related to any of the independent variables in the old subdivision. In the new subdivision the coping scale is negatively and significantly associated with education and number of applicances owned. This would seem to indicate that the higher the educational level, the less likely one is to choose a lifestyle change, retaining the desire for modern conveniences, such as appliances, while compensating by implementing minor conservation behaviors that can be accomplished without major changes in lifestyle. 
SIMULATED AND ACTUAL ENERGY CONSUMPTION

The energy requirements for heating and for cooling each of the three types of homes in the sample were simulated using the DOE 2.0A thermal transfer model. Results of the effort are presented in the first section of this chapter, with a discussion of the input parameter assumptions used in the simulation. Actual electricity consumption data for the homes is presented in surmary form in the second section and the data limitations are identified. In the third section, the actual and simulated energy data use are compared and some possible explanations for the differences are discussed.

\section{SIMULATION OF ENERGY CONSUMPTION}

To provide a basis for comparison, the energy performance of both the new and old subdivision houses was simulated using the DOE 2.0A computer program. This program uses hourly weather data for a "typical" meteorological year, which is actually a composite of many years of climatic data. Because of the differences between the typical weather data and the actual weather faced by the residences during 1980 and 1981, expected versus actual energy use comparisons were made on a Btu per degree day basis. Climatic factors such as solar radiation and wind velocity are not taken into account due to insufficient data.

The houses were modeled and built with electric furnaces and central air conditioning. A coefficient of performance or C.0.P. of 2.3 was assumed for the air conditioning equipment. The simulations were based on thermostat settings of $70^{\circ} \mathrm{F}$ in the winter and $78^{\circ} \mathrm{F}$ in the summer. Energy performance of the houses was simulated in a manner thermally consistent with actual construction practices. Several factors however may have caused the actual energy consumption to deviate from the computer estimates. One factor is that the estimates presented are averages for houses modeled facing each of the four major compass orientations. Actual orientation of a house may cause the house to have a slightly larger or smaller heating load. However, because of the relatively small window area in the houses and the uniform distribution of the glass on each of the walls, variations in orientation were expected to have minimal impact on the loads. 
A problem with the DOE 2.OA computer program was recognized after completion of the simulations. The 2.0A program did not take inter-zone heat transfers into account. This is particularly important with respect to the attic and garage, which were modeled as separate unconditioned zones. By not mode1ing energy to flow between the house and the attic or garage, the model effectively assumed the ceiling beneath the attic and the walls adjacent to the garage to be perfectly insulated. This would tend to cause the model to underestimate the conditioning loads by approximately 10 to 15 percent. The problem would be even more pronounced in the case of tri-level houses, which have both a wall and a floor adjoining the garage space. This problem has been corrected in the revised DOE 2.1 model.

Another, as yet unresolved, shortcoming of the computer simulations is an inability to account for the temperature differential which occurs in interior spaces. Since the air close to the ceiling is typically $10^{\circ}$ to $15^{\circ} \mathrm{F}$ warmer than the average room temperature, the heat flux through ceilings is consistently underestimated. This has the effect of underestimating heating loads, particularly in houses with lower levels of ceiling insulation.

Results of the simulation of energy requirements are shown in Table 12 for both the old and the new subdivision homes. The heating and cooling requirements are given separately for each of the three basic house models found in the subdivisions. Estimates of energy required for heating the three models seem to be most strongly influenced by the surface to volume ratios of the buildings. The tri-level has a relatively high ratio of exposed surface to volume of insulated living area and the highest heating energy requirements. The cooling energy requirements show the effect of surface area less consistently. In particular, the requirements of the ranch house are dominated by the beneficial effect on cooling energy requirements of a large roof overhang.

\section{ACTUAL ELECTRICITY CONSUMPTION}

At the time the survey was conducted most of the new homes had been occupied for less than a year. Cooling season data were unavailable for the majority of these homes, so only heating season data for the old and new 
TABLE 12. DOE 2.0A Simulations for the Subdivisions(a)

\begin{tabular}{|c|c|c|c|c|c|c|}
\hline \multirow[b]{2}{*}{ House Model } & \multicolumn{3}{|c|}{ Heating (Btu/HDD $\left./ \mathrm{ft}^{2}\right)$} & \multicolumn{3}{|c|}{ Cooling $\left(\mathrm{Btu} / \mathrm{CDD} / \mathrm{ft}^{2}\right)$} \\
\hline & $01 d^{(b)}$ & $\mathrm{New}(\mathrm{C})$ & Difference & $01 d^{(b)}$ & $\mathrm{New}(\mathrm{C})$ & Difference \\
\hline $\begin{array}{l}\text { Two Story } \\
\left(1417 \mathrm{ft}^{2}\right)\end{array}$ & 6.30 & 4.79 & $-24 \%$ & 2.67 & 2.44 & $-02 \%$ \\
\hline $\begin{array}{l}\text { Ranch } \\
\left(1265 \mathrm{ft}^{2}\right)\end{array}$ & 6.30 & 4.88 & $-23 \%$ & 2.18 & 1.97 & $-01 \%$ \\
\hline $\begin{array}{l}\text { Tri-level } \\
\left(1059 \mathrm{ft}^{2}\right)\end{array}$ & 7.30 & 5.69 & $-22 \%$ & 2.81 & 2.58 & $-08 \%$ \\
\hline
\end{tabular}

(a) Assuming 5300 heating degree days, 1000 cooling degree days, with a $65^{\circ} \mathrm{F}$ base.

(b) R-11 wall and R-19 ceiling insulation

(c) R-19 wall and R-38 ceiling insulation

subdivisions are compared. Heating season data for electricity consumption was available for the entire sample. Unfortunately, it is likely that use of this data alone neglects a substantial portion of the total heating energy inputs to the homes. All of the new homes have either heatilator fireplaces or woodstoves or both and half of the older homes have woodstoves. The data suggest that wood was used as the primary energy source in a number of the older homes where wood stoves had been retrofitted.

The average electricity consumption levels in houses of each model and for each subdivision as a whole are shown in Table 13. In the new subdivision the relative levels of electricity consumption are consistent with expectations based on surface-to-volume ratios of the homes, though the range of consumption levels is greater than expected. In the older subdivision, there is inconsistency in the relative levels of electricity consumption among the models. Some explanation for this may be found in the distribution of retrofitted woodstoves, however. While only one ranch and one two story home have woodstoves, two thirds of the tri-levels do. As a result, the measured electricity inputs in the tri-levels may understate average heating energy consumption to a greater extent than is the case in the other models. 
TABLE 13. Actual Electricity Use During the Heating Season

\begin{tabular}{|c|c|c|c|}
\hline \multirow[b]{2}{*}{ House Mode 1} & \multicolumn{3}{|c|}{ Mean Total Consumption (a) } \\
\hline & 01d & New & Difference \\
\hline Two Story & 7.54 & 5.02 & $\begin{array}{c}2.52 \\
(-33 \%)\end{array}$ \\
\hline Ranch & 6.16 & 8.30 & $\begin{array}{c}2.14 \\
(+34 \%)\end{array}$ \\
\hline Tri-Leve 1 & 7.16 & 10.21 & $\begin{array}{c}3.05 \\
(+43 \%)\end{array}$ \\
\hline Weighted Average(b) & 7.08 & 8.28 & $\begin{array}{c}1.20 \\
(+17 \%)\end{array}$ \\
\hline
\end{tabular}

(a) Actual energy use includes appliances, lighting and hot water as well as heating.

(b) Weighted by the proportions of each house model in the sample

Conversely, the apparently greater energy requirement per $\mathrm{ft}^{2}$ for heating the tri-levels may have provided more of an incentive to install a woodstove there than in the other models.

While the new two story homes used less electricity than similar older homes, the other models and the new subdivision as a while used more electricity per $\mathrm{ft}^{2}$ on average. As shown in Table 13, the new homes used 17 percent more electricity. This is in spite of construction practices designed to reduce energy consumption for heating more than 20 percent. A major portion of the higher consumption levels in the new subdivision is probably due to the higher thermostat settings found there. Table 14 presents the mean thermostat and water heater settings reported in each subdivision and separately for homes with and without woodstoves in the older subdivision. These figures indicate that more electricity-consuming settings were chosen in the new subdivision, particularly in the critical area of winter night temperature. While this appears to indicate that the occupants are enjoying greater comfort, the evidence is inconclusive since the electric heat may only be used as a backup system in some of the older homes with woodstoves. 
TABLE 14. Comparison of Mean Temperature Settings and Electricity Consumption

\begin{tabular}{|c|c|c|c|c|c|}
\hline & \multicolumn{4}{|c|}{ Temperature Settings } & \multirow[b]{2}{*}{$\begin{array}{l}\text { Electricity } \\
\text { Btu/HDD/SF }\end{array}$} \\
\hline & $\begin{array}{l}\text { Winter } \\
\text { Day } \\
\end{array}$ & $\begin{array}{l}\text { Winter } \\
\text { Night }\end{array}$ & Sumner & $\begin{array}{l}\text { Water } \\
\text { Heater } \\
\end{array}$ & \\
\hline $\begin{array}{l}\text { 0ld Subdivision } \\
\text { With Woodstoves } \\
\text { Without Woodstoves }\end{array}$ & $\begin{array}{l}66.4 \\
64.6 \\
67.9\end{array}$ & $\begin{array}{l}61.5 \\
60.25 \\
62.7\end{array}$ & $\begin{array}{l}75.9 \\
78.9 \\
73.3\end{array}$ & $\begin{array}{l}1.75 \\
1.57 \\
2.00\end{array}$ & $\begin{array}{l}7.09 \\
5.80 \\
8.38\end{array}$ \\
\hline New Subdivision & 67.9 & 64.8 & 75.1 & 1.90 & 8.28 \\
\hline
\end{tabular}

(a) Category $1=120^{\circ}, 2=140^{\circ}$

\section{COMPARISON OF RESULTS}

The simulation of energy requirements indicated lower requirements for the newer homes of all model types as indicated in Table 15. Measurement of actual electricity use showed higher consumption in the new subdivision except in the two story homes. However, there is no bas is for concluding that total energy consumption was higher in the newer homes.

The single most important reason for the differences between actual and estimated energy consumption is the lack of data for woodstove use. The consumption data that were compared to the simulations were only for electricity. Heating with wood could displace upwards of 50 percent of the heating load and could therefore be the cause of a significiant portion of the discrepancy with the computer estimates.

Actual consumption could also differ from the computer estimates because the internal loads of the houses were accounted for in the simulations through use of an assumed average profile. Actual internal loads would vary according to the number of occupants and the number, size, and use characteristics of appliances. Although the effects of such variations on the total conditioning loads are probably small, large differences could occur in electricity use for lighting and appliances which would have some effect on the utility bills used to estimate consumption. 
TABLE 15. Comparison of Simulated and Actual Electricity Use for Heating in the 0ld and New Subdivisions

House Mode 1

Two Story

Ranch

Tri-Leve 1

Weighted Average ${ }^{(a)}$

\section{Simulated Difference}

$-24 \%$

$-23 \%$

$-22 \%$

$-26 \%$
Actual Difference

$-33 \%$

$+34 \%$

$+43 \%$

$+17 \%$

(a) Weighted by proportions of each house model in the sample. The magnitude of the weighted average differences in simulated energy use across subdivisions is due to the variation in the proportions of each house model included in each subdivision.

Differences between actual and estimated energy consumption could also arise from the modeling assumption that occupants of the houses manually open the windows to ventilate the house for cooing purposes when exterior temperatures allow. Failure to do so would increase cooling loads, while carelessness, such as leaving doors and windows open in the winter, would increase heating loads. The temperature settings are another factor that could certainly cause deviation of actual consumption from the computer estimates. The simulations assume thermostat settings of $70^{\circ} \mathrm{F}$ in the winter and $78^{\circ} \mathrm{F}$ in the summer. Occupants of both subdivisions reported settings that were generally lower in both winter and sumer. 


\section{INVESTMENT AND PURCHASING DECISIONS}

One of the key issues in assessing the need for and potential response to energy conservation oriented regulation is whether and to what degree market incentives result in energy conservation. To explore aspects of this question the households surveyed were asked several questions pertaining to housing purchase and energy conserving investment decisions. In the following sections their responses are reported and then discussed in a brief summary.

\section{FACTORS IN DECISION MAKING}

Two questions pertaining to the purchase decision process were included. The first asked respondents to indicate the importance of various housing attributes to their home purchase decision. Attributes were rated on a five point scale from unimportant to very important. Table 16 shows the relative ranking of these attributes for the group as a whole. Not unexpectedly, purchase price was the predominant consideration. The only explicit cost item included in the list, expected fuel bills, was eleventh in the ranking. Apparently, home buyers' concerns with energy costs are expressed indirectly through their evaluation of insulation (third) and heating and cooling systems (ninth).

The second related question addressed the purchase decision process more generally. Respondents were asked what motivates them to make energy conserving purchases. Results are given in Table 17 indicating the percentage of respondents selecting each factor as the most important. Information about the effect and cost effectiveness of the investments appeared to be of paramount importance. Nearly $60 \%$ of the respondents indicated that either information regarding energy savings or information regarding the pay back period is most important.

\section{CONSERVATION INVESTMENTS}

A question previously used in surveys by Professional Builder Magazine was included in the questionnaire to investigate willingness to pay for energy conservation. The responses are summarized in Table 18. There was a clear 
TABLE 16. Factors Reported to Affect House Purchase DecisionsListed in Order of Importance

1. Purchase Price

2. Neighborhood

3. Insulation

4. Floor plan

5. Quality of construction

6. Garage

7. Location

8. House size

9. Heating and cooling system

10. Number of rooms

11. Expected fuel bills

12. Size of lot

13. Exterior appearance

14. Sizes of rooms

15. Window placement

16. Style

17. Adequate natural lighting

18. Number and type of appliances

19. Effective cross ventilation

20. View

TABLE 17. Factors Influencing Respondents' Energy Conservation Investment Decisions

Knowing payback period

Knowing how much energy would be saved

Being able to do part or all yourself

Federal tax credits

$11 \%$

Conservation ethic

Availability of low interest loans

No response

Note: Percentages do not add to 100 due to rounding 
TABLE 18. Respondent Willingness to Pay an Additional $\$ 600$ for a Home to Save $\$ 100$ in Energy Costs Annually

Spend the additional $\$ 600 \quad 44 \%$

Be willing to spend more to save more $50 \%$

Not spend the $\$ 600$ because costs take too long to recover 0

Not spend the $\$ 600$ because the savings are not believable 0

No response $6 \%$

concensus (94 percent) that people would be willing to pay at least $\$ 600$ to save at least $\$ 100$ in fuel costs annually. A willingness to spend more was indicated by 50 percent of the respondents. Thus it appears that most, if not a11, of the respondents are willing to pay a realistic amount to obtain the savings available from energy conserving investments.

Respondents were also queried regarding the acceptability of a variety of energy related features if they were buying a new house. On the bas is of the respondent's ratings of these features, they are grouped by relative acceptability in Table 19. These features are not listed in any particular order within the three acceptance categories. The favorable opinion of partial earth sheltering was somewhat surprising considering its rarity in the survey area. Conversely, fireplaces, which are commonly installed in new homes, were clearly rejected. A preference for woodstoves over fireplaces was quite apparent. The rejection of night set-back thermostats was unexpected and the reasons are unknown since these devices are relatively inexpensive and cost effective.

\section{SUMMARY}

Provided that the survey responses are indicative of the actual behavior of respondents, they are willing to purchase most energy conserving features they believe to be effective. If there is a lack of energy conserving investment, it may be due to lack of consumers' information about the costeffectiveness of various features. Failure on the part of builders to incorporate energy conserving features may similarly result from a lack of know ledge of consumer preferences. 
TABLE 19. Acceptability of Energy Related Features to Homeowners

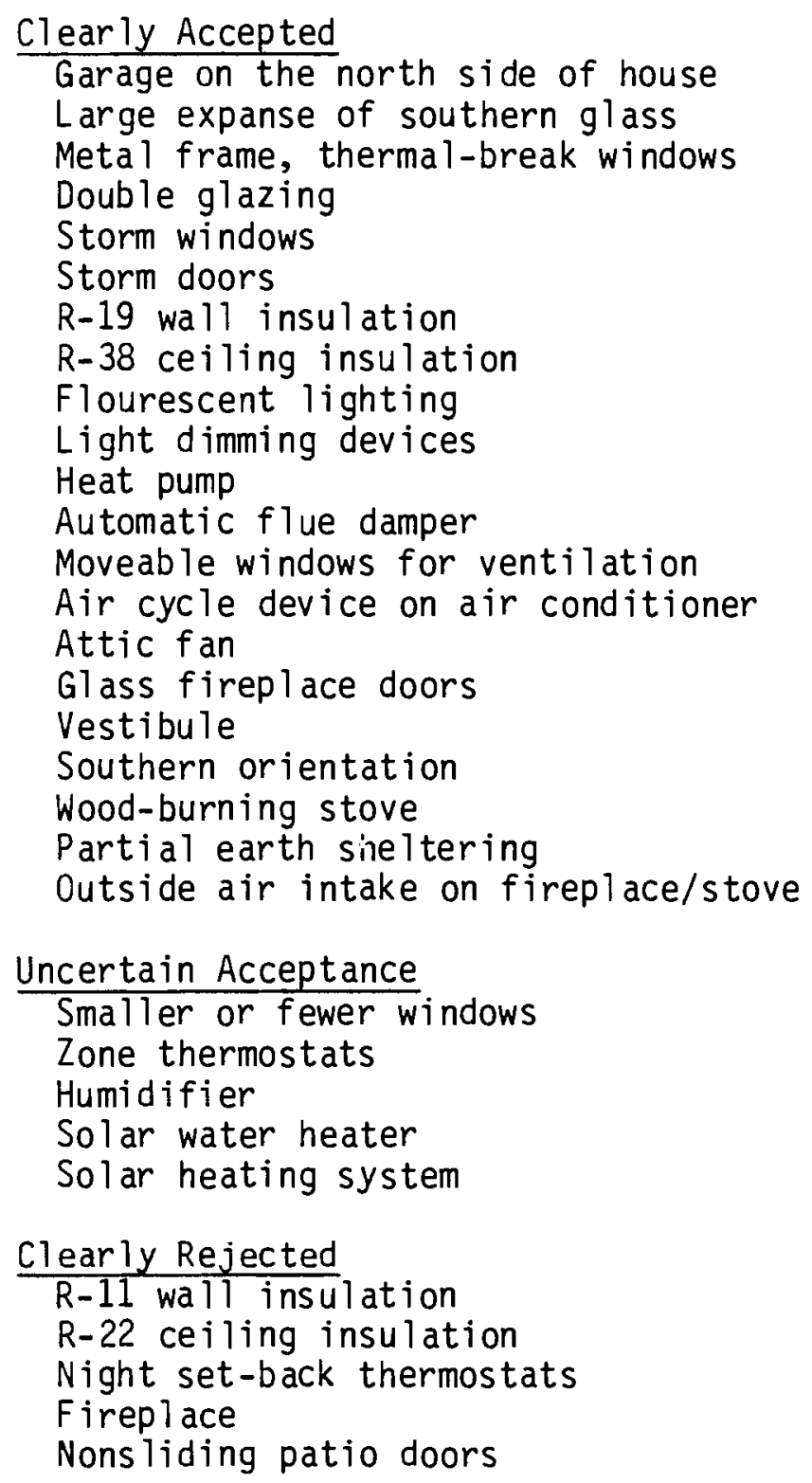




\section{RESEARCH IMPLICATIONS}

This section contains a brief discussion of some of the implications of this research. First policy implications of the research findings are discussed. Second, some methodological changes which would improve future research along the lines of this study are suggested.

\section{POLICY IMPLICATIONS}

The relative thermal characteristics of houses in the old and the new subdivisions result in a projected requirement of almost $25 \%$ less heating energy to maintain an equivalent indoor temperature in the new homes than in the old. This projected reduction in the heating energy requirement due to greater thermal efficiency is not reflected in actual electricity use, however. Heating season data for the subdivisions indicate 17 percent more electricity per $\mathrm{ft}^{2}$ is used in the new subdivision than in the old. While this result appears to be due to economic rather than physical factors, the actual difference between the subdivisions in total energy use is uncertain because data on wood consumption is unavailable.

There are differences in two characteristics of the subdivisions which economic theory indicates would lead to higher energy consumption in the new subdivision. First, the gross family incomes reported by households in the new subdivision were significantly higher than those in the old. Second, electricity prices in the new subdivision are half the old subdivision price. Because complete experimental control was lacking and the sample is too smal1 to permit statistical control, the magnitudes of the income, substitution and price effects cannot be determined.

Even without the effects of higher incomes and lower price on electricity consumption in the new subdivision, there could be higher energy consumption levels there due to lower marginal costs of comfort. The investment in increased insulation resulting in greater thermal efficiency also results in lower costs of heating in the new subdivision than in the old, all other things equal. This being the case, owners of new homes can enjoy higher 
comfort levels for the same or lower fuel cost. The more energy intensive thermostat settings found in the new subdivisions tend to confirm this.

The mean electricity consumption in the new houses and the old houses without woodstoves is virtually equal, 8.28 and $8.38 \mathrm{Btu} / \mathrm{HDD} / \mathrm{ft}^{2}$ respectively. With the same electricity input and the differing technologies, occupants of the new subdivision are almost certainly enjoying greater comfort. When the new homes, which have woodstoves or relatively efficient fireplaces as standard equipment, are compared with the old homes that have woodstoves, the higher energy consumption rate in th new subdivision is more apparent. The old homes used a mean of $5.80 \mathrm{Btu} / \mathrm{HDD} / \mathrm{ft}^{2}$ of electricity plus some unknown quantity of wood while the new homes may also have used wood in addition to $8.28 \mathrm{Btu} / \mathrm{HDD} / \mathrm{ft}^{2}$. This represents over 40 percent higher electricity consumption in the new subdivision. Of course, this difference may be partially attributable to a higher rate of substitution of wood for electricity in the older subdivision due to higher electricity price.

There has been considerable effort on the part of the Department of Energy to improve the energy efficiency of buildings. The question is, will making buildings more energy efficient reduce energy use? One of the implications of this study is that a clear point of reference is needed from which to measure energy conservation. An energy efficient house will require less energy for space conditioning to a given comfort level than an otherwise identical house with an identical pattern of occupant use. Thus, installation of efficient technology does result in energy conservation. However, an energy efficient house will not necessarily use less energy than an inefficient one in which lower comfort levels are maintained or in which the pattern of use is less energy intensive. As a result, projection of conservation due to technology change must consider the effects of the technology on energy use and the effects of behavior.

In addition to difficulties in measuring conservation, there are problems in accounting for energy use. Much of the reduction in electricity usage in the old subdivision houses with wood stoves does not represent energy conservation per se, but is actually due to substitution of wood combustion for electricity in space heating. Capital investment which permits fuel 
substitution in buildings, unlike capital investment in insulation, results in electricity demand reduction that is totally dependent on occupant behavior. Should any wood supply or demand change result in higher wood prices relative to electricity, house occupants may adapt to the change by switching back to electricity.

\section{METHODOLOGICAL IMPLICATIONS}

The most severe problems associated with the methodological and analytical procedures employed in this study involve: 1) the lack of opportunity to properly construct the attitudinal components of the instrument and; 2) the limitations resulting from small sample size. Scale validation and increased sample size would provide a better opportunity to assess the behavioral determinants of energy consumption. In addition, a large sample size will permit a regression analysis that will estimate the relative importance of various nonphysical attributes. A larger sample size would also present the opportunity for a preliminary causal analysis with a sufficient number of variables to provide a more realistic household energy consumption model.

One significant challenge in studies such as this is the integration of sociodemographic, attitudinal and behavioral determinants with physical and thermal characteristics of structures assessed in simulation models such as DOE 2.1. A better understanding of the former determinants will increase the utility of the modeling effort. In addition, it may provide the basis for focusing future policy thrusts in a direction that will maximize conservation impact. 

APPENDIX A

HOMEOWNER'S QUESTIONNAIRE 
January 24, 1980

\section{Battelle}

Pacific Northwest Laboratories P.O. Box 999

Richland, Washington U.S.A. 99352

Telephone (509) 942-4356

Telex 15-2874

Dear Head of Household:

For the past several years Battelle has been involved in developing ways to reduce the use of fuels in heating and cooling buildings. At the Pacific Northwest Laboratory (PNL) in Richland, Washington, we are carrying out research under contract to the Department of Energy to estimate the costs and benefits of various energy conservation techniques.

To obtain the information needed to continue improving the energy and economic efficiency of homes, we ask that you complete the attached questionnaire and return it in the enclosed envelope. From information regarding your home and the energy conserving actions you take, we will estimate its likely energy use. To verify the accuracy of our estimates, we would like your permission to obtain fuel consumption information about your home from the local utilities. Please sign the permission form and return it with your questionnaire. The information you provide will be kept confidential and will only be used in our statistical analysis.

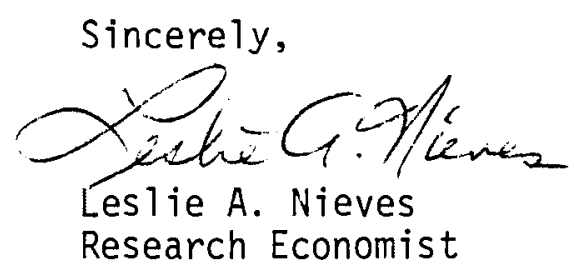

Attachment 


\section{QUESTIONNAIRE}

Please Circle the Number Representing the Response that Applies to You

1. Do you rent or own your present dwelling?

$$
\begin{aligned}
& \text { Rent ........................ } 1 \\
& \text { Own or buying.................... . . } 2 \\
& \text { Free housing .................. } 3
\end{aligned}
$$

Do Not Write in This Column

2. How many people live in your home? (Count all children and any relatives, friends, or boarders living with you.)

How many people who live in your home are in each age group?

3. Less than 6 years

4. 6 to 13 years

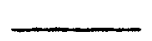

5. 13 to 18 years

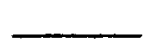

6. over 18 years

7. What is your race or ethnic group?

Caucasian (white)................. . . 1 Black................... . . . . . 2 Oriental ................. . . . 3

Spanish American . . . . . . . . . . . . . 4

Native American . . . . . . . . . . . . . 5

Other or mixed . . . . . . . . . . . . 6

Indicate the number of years of formal schooling completed:

8.

You

9. Spouse 
10. Into which of the following categories does your total annual income, before taxes, fall?

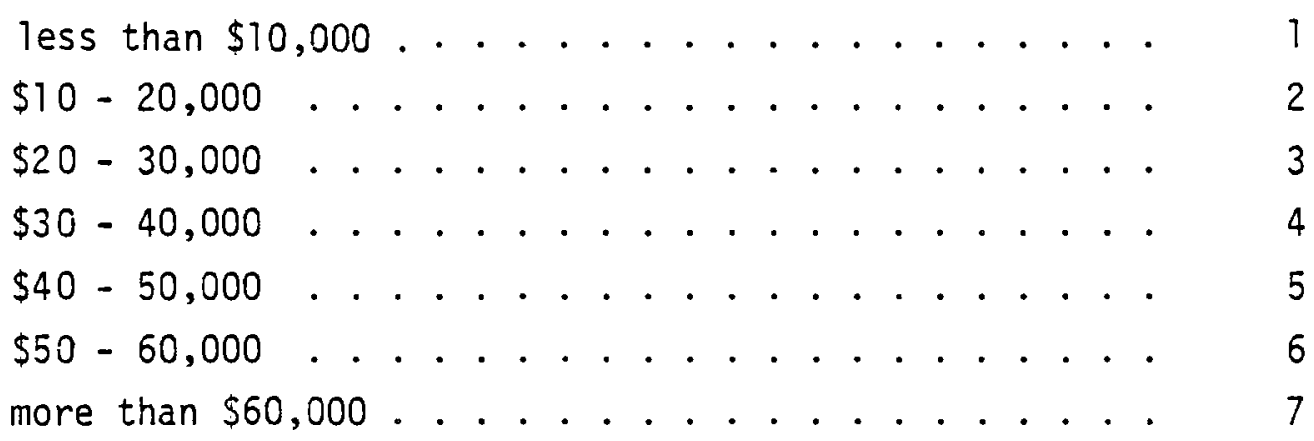

Do Not

Write in

This column

Circle the employment status of the adults living in your house:

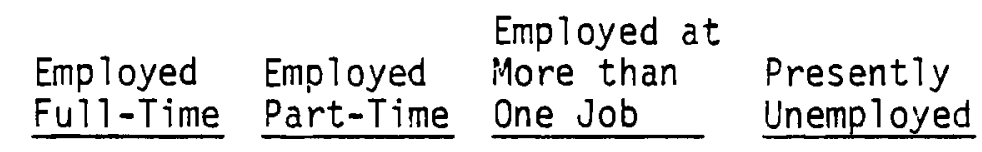

$11 . \quad$ You

2

3

4

$\overline{(76)}$

12.

Spouse

1

2

3

4

(17)

13. Other

12

3

4

$\overline{(15)}$

14. Have you had an energy audit performed for your house?

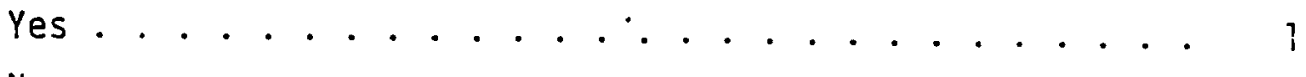

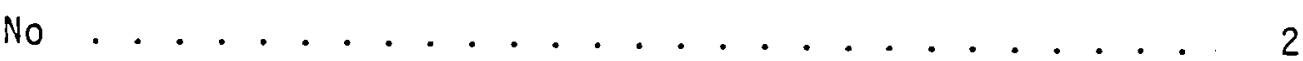

15. lo: many months haye ynu lived at this address? montins. 
Indicate whether or not you do each of the following by circling the number of the most appropriate response for you:

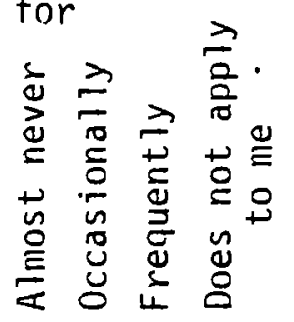

15. Turn off lights when not being used .... 12334

17. Close drapes at night.......... 12234

13. Close fireplace damper when not in use ... 1234

19. Take short showers rather than baths.... 1234

20. Turn dishwasher off before the drying cycle and open door.................. 12234

Do Not Write in This Column

$\overline{(22)}$

(23)

(24)

(25)

(26)

21. Change furnace filters ........ 12334

22. Wash clothes in warm or cold water and rinse in cold water ................... 12234

23. Use clothesline for drying ....... 1234

24. Open windows to cool the house ..... 1234

25. Close off vents in unused rooms ....... 12234

26. Flush out the bottom of the hot water heater $\begin{array}{llll}1 & 2 & 3 & 4\end{array}$

\section{Annual maintenance/inspection of heating and} cooling equipment................ 12234 
Do Not Write in This Column

At what setting do you keep the thermostat in your home?

28. During the day in winter. . . . . .

29. During the night in winter . . . . .

$+$

30. During the summer (if air-conditioned)

31. At what temperature do you normally set your water heater?

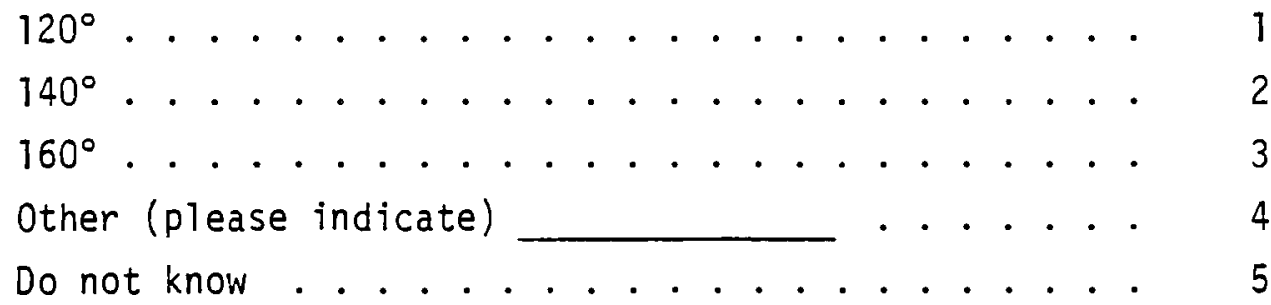

$\overline{(36,37)}$

$\overline{(38,39)}$

32. Circle the number for the factor which is most important to you in deciding what energy conserving investments to make:

knowing how long it would take for these improvements to pay for themselves in lower energy costs . . . . .

Being able to reduce out-of-pocket expenses by doing some of the work yourself . . . . . . . . . . . . .

knowing that you are eligible for a federal tax credit if you make these improvements . . . . . . . . . .

Being able to obtain a loan on good terms to cover part or all of the cost of these improvements . . . .

Feeling that energy conservation is an important national goal that you want to help attain . . . . .

knowing how much energy would be saved by the investment ................... 6 Other 
33. Which of the following have you done in the last 3 years to reduce utility bills or energy consumption?

Use stove or fireplace for heating . . . . . . . . 1

Purchase smaller cars ............. . . 2

Ride bicycles ................ . . . 3

Use carpools ................... . . . 4

Lower thermostat during winter . . . . . . . . . 5

Raise thermostat during summer . . . . . . . . 6

Reduce water temperature in home . . . . . . . . 7

Use less hot water. . . . . . . . . . . . 8

Reduce usage of small appliances . . . . . . . . 9

Reduce usage of major appliances . . . . . . . 10

Reduce travel to distant vacation areas . . . . . 11

other (indicate) 12

34. Which of the following appliances do you have in this house?

Refrigerator, frost-free . . . . . . . . . . 1

Freezer .. . . . . . . . . . . . . . . 2

Dishwasher . . . . . . . . . . . . . 3

Clothes washer................. 4

Clothes dryer ................. . . 5

Power tools .................. . . 6

Self-cleaning oven... . . . . . . . . . 7

Other (indicate) 
Indicate the importance to you of the following factors in choosing vour home:

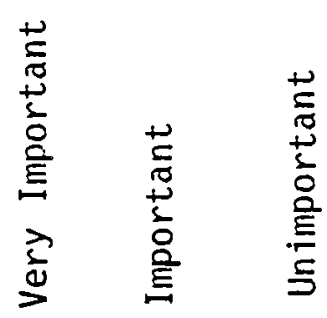

35. Size of house (total number of sq. ft.). . 12345

Style........................... 12345

Do Not

Write in

This Column

37. Number of rooms............ 12345

33. Sizes of rooms ............ 12345

39. Floor plan (arrangement of rooms).... 12345

40. Window placement .......... 12345

41. Quality of construction....... 12345

Exterior appearance.............. 12345

43. Effective cross ventilation....... 12345

44. Adequate natural 1ighting........ 12345

45. Type of heating and cooling equipment... 12345

46. Number and type of major appliances (refrigerator, range).......... 123345 


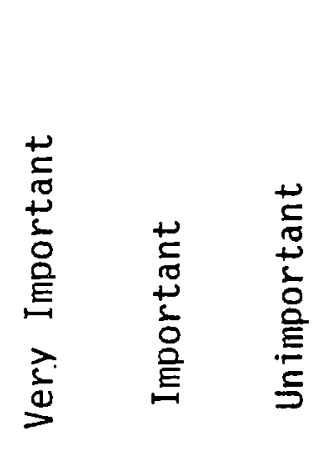

49. Purchase price........... 123345

50. Neighborhood .............. 12345

51. Expected fuel bills ......... 123345

$\overline{(58)}$

(60)

52.

view......................... 1223345

53. Location................... 122344

54. Size of lot (garden, lawn, etc.) .... 1423445

55. Other

56. In the U.S. today, do you think energy shortages are:

A major problem .............. . 1

A moderately important problem .......... 2

No problem ................. 3

No shortage ..................... 4 
Please circle the number which best corresponds to your opinion about how the energy situation can be improved. There are no right or wrong responses.

Do Not

57. Lower fuel prices even if supplies are tight $1 \quad 2 \quad 3 \quad 4 \quad 5$

58. Raise fuel prices to curb demand ..... 12345

59. Improve the efficiency standards for building, equipment and industrial processes so less energy will be required ......... 123345

60. Accelerate nuclear energy production : . . 12345

Accelerate coal production ....... 12345

Develop offshore sources of $0 i 1$ and natural

62. gas.............................. 2345

63. Obtain more fuel from other countries . . 12345

64. Ration fuet ..................... 12345

Change style of living to use less energy 
Indicate which of the following features have been added to

Do Not

Write in

your home or will definitely be added during 1980.

This Column

67. Insulation in ceiling (__ inches) .... $1 \begin{array}{lll}1 & 2 & 3\end{array}$

68. Insulation in walls (_ inches)..... 1 . 23

69. Weatherstripping around windows and doors . . $\begin{array}{llll}1 & 2 & 3\end{array}$

70. Storm windows ............. 123

71. Storm doors ................ 123

72. Caulking around windows ......... 123

73. "Night set-back" thermostat ........ 123

74. Attic fan ................... 123

75. Humidifier.............. 1223

76. Glass fireplace doors .............. 123

77. Solar water heater........... 123

78. Woodburning stove ............ 123

79. Automatic flue damper .......... 1233

30. Water heater insulation ......... 123 
81. Are there any specific reasons why you do not plan to add energyconserving features this year?

We are satisfied with the house as it is ....... 1

We cannot afford to make any more changes ... . . . 2

We are not convinced that any changes will cut energy costs much ............... . . 3

We do not plan to live here for a long period of time 4

other

82. Suppose you were buying a new home and the builder said that by spending $\$ 600$ more at the time of construction, your fuel bills would be reduced by about $\$ 100$ each year. What would you do?

Spend the additional $\$ 600 \ldots . . . . . . . . .1$

Be willing to spend even more to save more . . . . . 2

Not spend the $\$ 600$ because costs take too long to recover 3

Not spend the $\$ 600$ because the savings are not believable 4

If you were planning to buy a new house in this area, which of the following energy saving features would you want it to have?

83. Cube-shaped house rather than ranchstyle .... 123

84. Greenhouse as part of house ......... 123

85. Garage on the north ............. 123

86. Large expanse of glass on south ....... 123

87. Smaller or fewer windows......... 123 


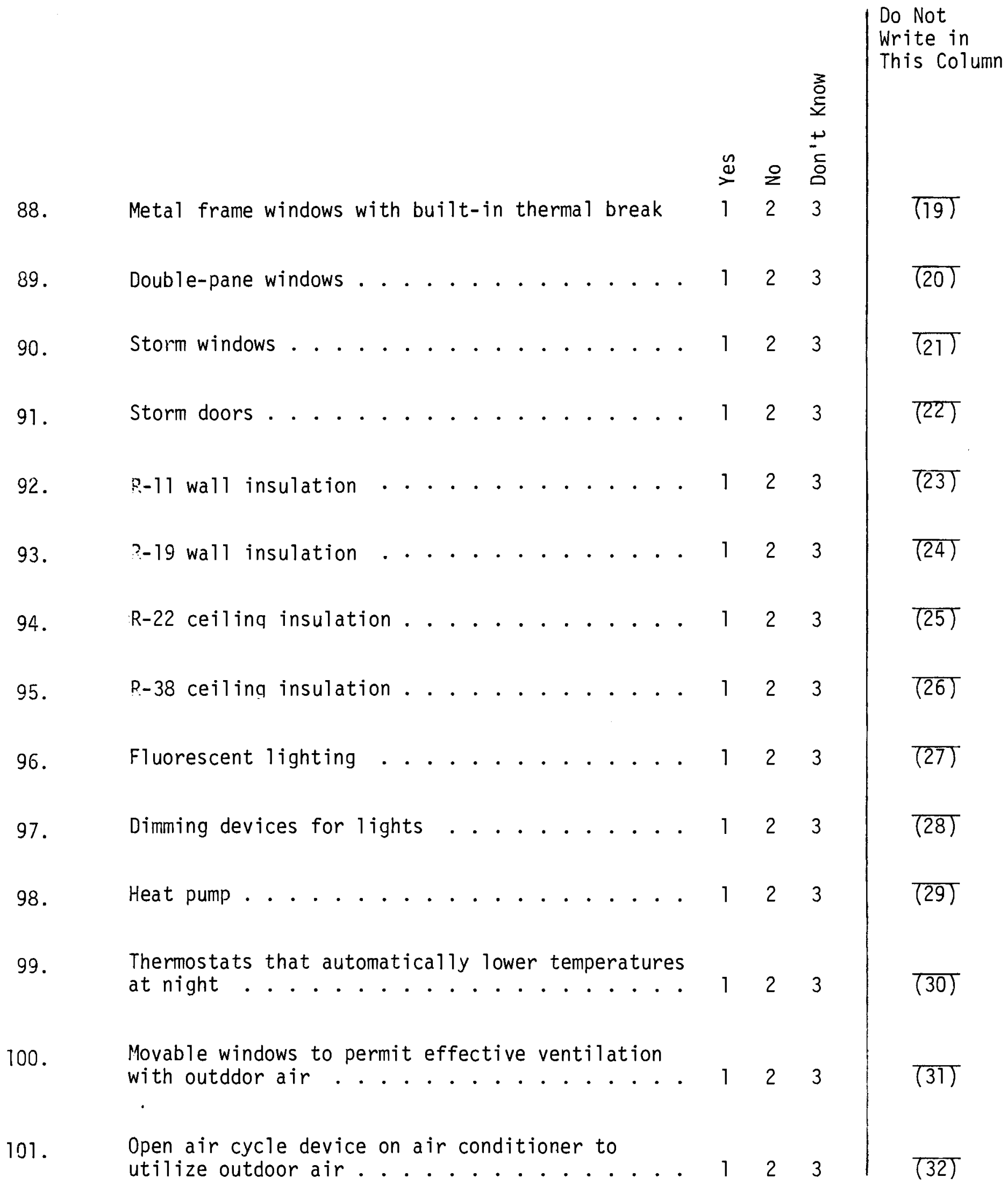


102. Thermostatically controlled attic fan..... 1223

I Do Not

Write in

This Column

103. Automatic flue damper on gas-fired furnaces . . $\quad 1 \quad 2 \quad 3$

(34)

$\overline{(33)}$

104. Individual room thermostats in all electric home 1223

105.

Humidifier ...................... 123

$\overline{(36)}$

105.

Solar water heater ............... 1223

(37)

107

Solar heating system ................ 123

108. Interior glass door to cover fireplace .... 123

109. Two door vestibule or entryway ....... 123

110. Landscaping for windbreaks and sun shielding . . $\quad \begin{array}{llll} & 2 & 3\end{array}$

111. Orientation of home to the south ....... 123

Fireplace.................... 123

113. Wood burning stove ............. 123

114. Lower level partially under ground ...... 123

115. Roof overhangs for window shading ...... 1233

116. Nonsliding patio doors (french style) . . . . 123 
APPENDIX B

HOMEBUYER'S QUESTIONNAIRE 
Pacific Northwest Laboratories P.O. Box 999

Richland, Washington U.S.A. 99352

Telephone (509) $942-4.356$

Telex 15-2874

Dear Home Buyer:

For the past several years Battelle has been involved in developing ways to reduce the use of fuels in heating and cooling buildings. At the Pacific Northwest Laboratory (PNL) in Richland, Washington, we are carrying out research under contract to the Department of Energy to estimate the costs and benefits of various energy conservation techniques.

We have contracted with the homebuilder to conduct a field test of energy conservation techniques which will enable us to refine our estimation procedures. To satisfy our research requirements the houses in this subdivision are being built with close to the best in energy conservation techniques currently available in a conventional, moderately-priced home. It is expected that the savings which will result from the conservation options offered in these homes will exceed their cost.

To obtain the information needed to continue improving the energy and economic efficiency of homes, we ask that you complete the attached questionnaire. From information regarding the home and optional features you choose, we will estimate its likely energy use. To verify the accuracy of our estimates, we would like your permission to obtain information about fuel consumption in your house from the local uti?ities.

A permission form is attached for your signature.

Thank you for your cooperation.

\section{Sincerely,}

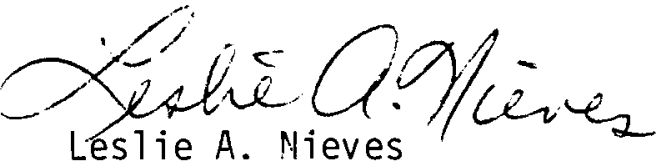

Leslie A. Nieves

Research Economist

Attachment 


\section{QUESTIONNAIRE}

Please Circle the Number Representing the Response that Applies to You

1. In what type of dwelling are you presently living?

Single family house . . . . . . . . . . . . . . . 1

Duplex . . . . . . . . . . . . . . . . 2

Apartment ...................... 3

Condominium .. . . . . . . . . . . . . . . 4

Mobile Home .. . . . . . . . . . . . . . . . 5

Rooming with someone else . . . . . . . . . . . 6

Other (please indicate) _ 7

Do Not

Write in

This Column

$(7,2)$

$\frac{1}{(3)}$

(4)

2. Do you rent or own your present dwelling?

Rent ........................ 1

Own or buying................... 2

Free housing . . . . . . . . . . . . . . 3

3. How many people will live in your new home? (Count all children and any relatives, friends, or boarders living with you.)

How many people who will live in your new home are in each age group?

4. Less than 6 years

(7)

5. 6 to 13 years

$(8)$

6. 13 to 18 years

(9)

7. over 18 years

$710)$ 
Do Not Write in This Column

8. What is your race or ethnic group? Caucasian (white)................. . . . 1 Black.................... . . . . 2 Oriental ................... 3 Spanish American . . . . . . . . . . . . 4 Native American . . . . . . . . . . . . . . 5 Other or mixed ................. . . . . 6

(11)

Indicate the number of years of formal schooling completed:

9. You

10. Spouse

11 Into which of the following categories does your total annual income, before taxes, fall?

less than $\$ 10,000$................. . . . 1

$\$ 10-20,000$................. . . . 2

$\$ 20-30,000$................ . . 3

$\$ 30-40,000$................ . . . . 4

$\$ 40-50,000$................. 5

$\$ 50-60,000$. . . . . . . . . . . . . . . . 6

more than $\$ 60,000$. . . . . . . . . . . . . . 7

Circle the employment status of the adults living in your house:

\begin{tabular}{llll} 
Employed & $\begin{array}{l}\text { Employed at } \\
\text { Full-Time }\end{array}$ & $\begin{array}{l}\text { Mart-Time } \\
\text { Pore than }\end{array}$ & $\begin{array}{l}\text { Presently } \\
\text { One Job }\end{array}$ \\
\hline
\end{tabular}

12.

You

1

2

13. Spouse

1

2

14. Other

1

2
(16)

3

4

(17)

3

4

(18)

3

4

$(12,13)$

$(14,15)$

\section{B. 2}


13. Have you had an energy audit performed for your present dwe 11 ing?

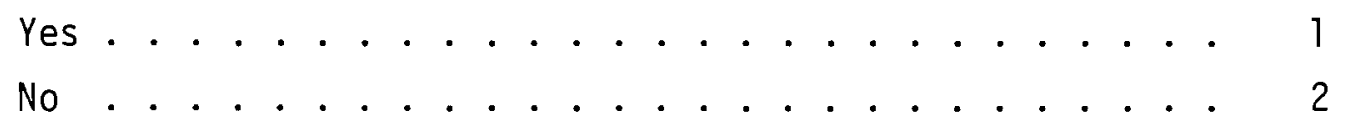

Indicate whether or not you take each action by circling the number of the most appropriate response for you:

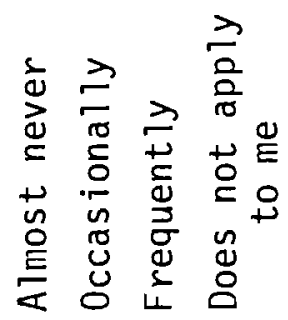

14. Turn off lights when not being used ..... 1234

15. Close drapes at night........... 1234

16. Close fireplace damper when not in use ... 1234

17. Take short showers rather than baths .... 1234

18. Turn dishwasher off before the drying cycle and open door................................ 1234

19. Change furnace filters .......... 1234

20. Wash clothes in warm or cold water and rinse in cold water ............................. 234

21. Use clothesline for drying ......... 1234

22. Open windows to cool the house ....... 1234

23. Close off vents in unused rooms ....... 1234

24. Flush out the bottom of the hot water heater $\quad \begin{array}{llll}1 & 2 & 3 & 4\end{array}$

25. Annual maintenance/inspection of heating and cooling equipment...................... 1234 
Do Not Write in This Column

$(35,36)$

$(37,38)$

$(39,40)$

29. At what temperature do you normally set your water heater?

30. Circle the number for the factor which is most important to you in deciding what energy conserving investments to make:

Knowing how long it would take for these improvements to pay for themselves in lower energy costs . . . .

Being able to reduce out-of-pocket expenses by doing some of the work yourself . . . . . . . . . . . . .

knowing that you are eligible for a federal tax credit if you make these improvements ............

Being able to obtain a loan on good terms to cover part or all of the cost of these improvements . . . .

Feeling that energy conservation is an important national goal that you want to help attain......

Knowing how much energy would be saved by the investment . . . . . . . . . . . . . . . 6

other 
Do Not Write in This Column

31. Which of the following have you done in the last 3 years to reduce utility bills or energy consumption?

Use stove or fireplace for heating . . . . . . . . 1

Purchase smaller cars .............. . 2

Ride bicycles .................. 3

Use carpools . . . . . . . . . . . . . . . . 4

Lower thermostat during winter. . . . . . . . . 5

Raise thermostat during summer . . . . . . . . 6

Reduce water temperature in home . . . . . . . . 7

Use less hot water . . . . . . . . . . . . 8

Reduce usage of small appliances . . . . . . . . 9

Reduce usage of major appliances . . . . . . . . . 10

Reduce travel to distant vacation areas . . . . . . 11

Other (indicate) 12

32. Which of the following appliances will you have in this new house?

Refrigerator, frost-free ............. 1

Freezer . . . . . . . . . . . . . . . 2

Dishwasher . . . . . . . . . . . . . 3

Clothes washer............... . . . 4

Clothes dryer ................ 5

Power tools .................. . . 6

Self-cleaning oven .............. . . 7

Other (indicate) 8 
Indicate the importance to you of the following factors in choosing this home:

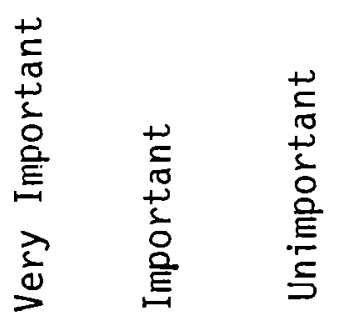

33. Size of house (total number of sq. ft.). . 12345

34. Style......................... 12345

Do Not Write in This Column

35. Number of rooms ........... 12345

36. Sizes of rooms ............ 12345

37. Floor plan (arrangement of rooms) . . . 123.45

38. Window placement .......... 12345

39. Quality of construction........ 12345

40. Exterior appearance .......... 12345

41. Effective cross ventilation....... 12345

42. Adequate natural lighting........ 12345

43. Type of heating and cooling equipment... 12345

44. Number and type of major appliances

(refrigerator, range)........ 12345

45.

Insulation ................ 12345

46.

Garage .

12345

(58)

B.5 


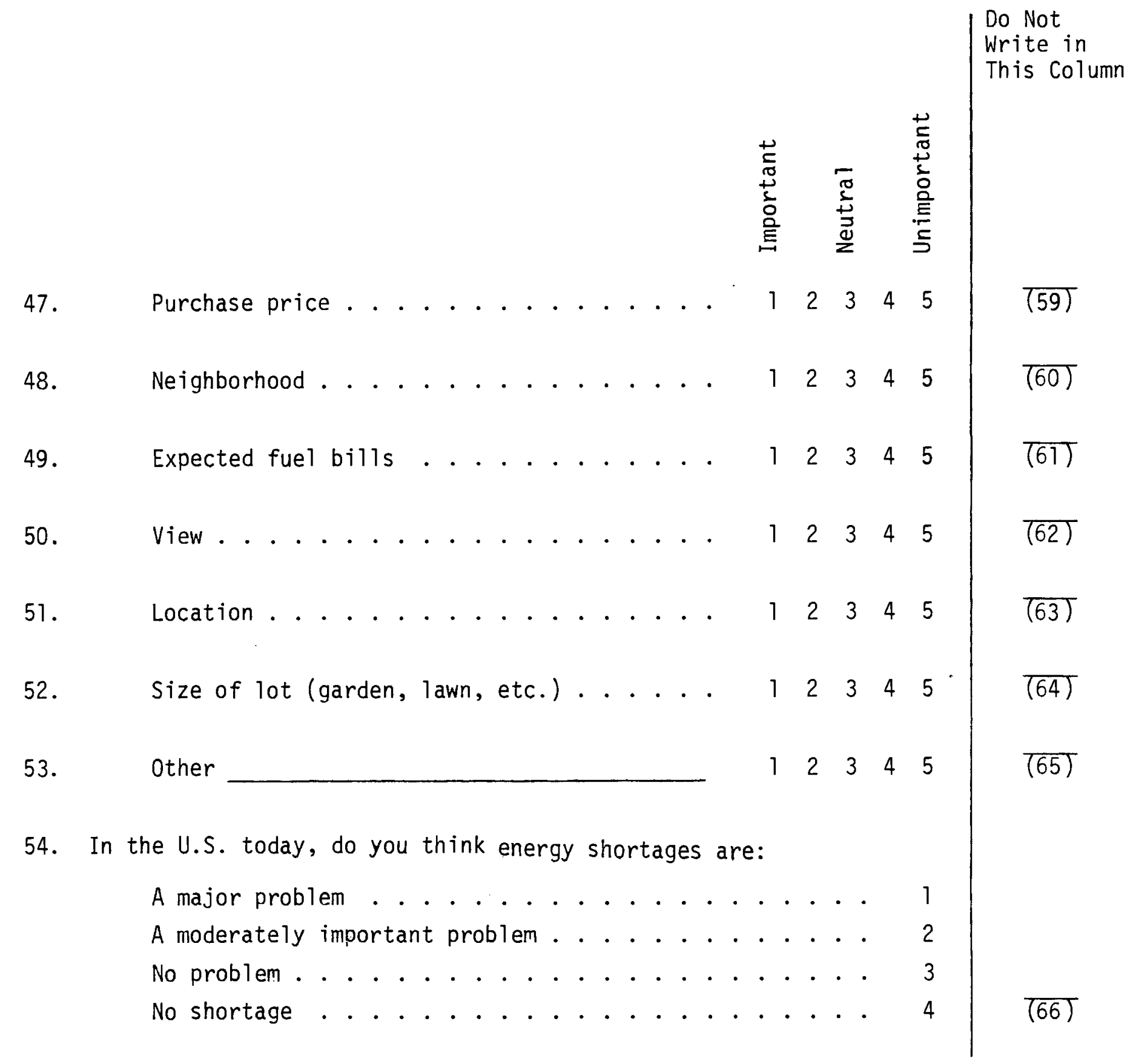


Please circle the number which best corresponds to your opinion about how the energy situation can be improved. There are no right or wrong responses:

Do Not Write in This Column

55. Lower fuel prices even if supplies are tight 123445

56. Raise fuel prices to curb demand..... 12345

$\overline{(68)}$

57. Improve the efficiency standaras for building, equipment and industrial processes so less energy will be required .......... 123345

58. Accelerate nuclear energy production... 12345

59. Accelerate coal production....... . 12345

Develop offshore sources of $0 i 1$ and natural

60. gas ............................... 12345

61. Obtain more fuel from other countries . . 12345

62. Ration fuel ................ 12345

63. Change style of living to use less energy $\quad \begin{array}{lllll}1 & 3 & 4 & 5\end{array}$ 


\section{DISTRIBUTION}

No. of

Copies

OFFSITE

A. A. Churm

DOE Patent Division

9800 S. Cass Avenue

Argonne, IL 60439

5 J. Binkley

Forrestal Building 1000 Independence Ave. Washington, DC 20585

S. P. Zakaria

U.S. Department of Energy

Conservation and Solar Applications

Room 6B-018

CS-63

Washington, DC 20545

27 DOE Technical Information Center

A. Jordan

Oak Ridge National Laboratory

Oak Ridge, TN 37830
No. of

Copies

W. J. Hopp

2462 Arrowwood

Ann Arbor, MI 48105

ONSITE

DOE Richland Operations Office

H. E. Ranson

26 Pacific Northwest Laboratory

T. J. Foley

R. Mazzucchi

A. Nieves (10)

L. Nieves (5)

J. Scherer

T. L. Willke

Publishing Coordination (2)

Technical Information KE (5) 


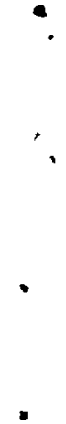

